\title{
Inner Ear Arginine Vasopressin-Vasopressin Receptor 2-Aquaporin 2 Signaling Pathway Is Involved in the Induction of Motion Sickness ${ }^{\mathbb{9}}$
}

\author{
Li-Hua Xu, ${ }^{3}$ Yao Yang, ${ }^{3}$ Hong-Xia Liu, ${ }^{3}$ Shui-Feng Xiao, Wen-Xia Qiu, Jin-Xing Wang, \\ Chen-Chen Zhao, Yuan-Hong Gui, Gui-Zhu Liu, Bin Peng, Xia Li, Guo-Hua Wang, \\ Xin Zhou, and Zheng-Lin Jiang \\ Department of Neurophysiology and Neuropharmacology, Institute of Special Environmental Medicine, Institute of Nautical \\ Medicine and Co-innovation Center of Neuroregeneration, Nantong University, Nantong, Jiangsu, China
}

Received December 9, 2019; accepted February 24, 2020

\begin{abstract}
It has been identified that arginine vasopressin (AVP), vasopressin receptor 2(V2R), and the aquaporin 2 (AQP2) signaling pathway in the inner ear play important roles in hearing and balance functions through regulating the endolymph equilibrium; however, the contributions of this signaling pathway to the development of motion sickness are unclear. The present study was designed to investigate whether the activation of the AVPV2R-AQP2 signaling pathway in the inner ear is involved in the induction of motion sickness and whether mozavaptan, a V2R antagonist, could reduce motion sickness. We found that both rotatory stimulus and intraperitoneal AVP injection induced conditioned taste aversion (a confirmed behavioral index for motion sickness) in rats and activated the AVP-V2R-AQP2 signaling pathway with a responsive $\mathrm{V} 2 \mathrm{R}$ downregulation in the inner ears, and AVP perfusion in cultured epithelial cells from rat endolymphatic sacs induced similar changes in this pathway signaling. Vestibular training, V2R antagonist mozavaptan, or PKA inhibitor H89 blunted these changes in the V2R-AQP2
\end{abstract}

pathway signaling while reducing rotatory stimulus- or DDAVP (a V2R agonist)-induced motion sickness in rats and dogs. Therefore, our results suggest that activation of the inner ear AVP-V2R-AQP2 signaling pathway is potentially involved in the development of motion sickness; thus, mozavaptan targeting AVP V2Rs in the inner ear may provide us with a new application option to reduce motion sickness.

\section{SIGNIFICANCE STATEMENT}

Motion sickness affects many people traveling or working. In the present study our results showed that activation of the inner ear arginine vasopressin-vaspopressin receptor 2 (V2R)-aquaporin 2 signaling pathway was potentially involved in the development of motion sickness and that blocking V2R with mozavaptan, a V2R antagonist, was much more effective in reducing motion sickness in both rat and dog; therefore, we demonstrated a new mechanism to underlie motion sickness and a new candidate drug to reduce motion sickness.

\section{Introduction}

Motion sickness is induced when humans encounter abnormal vestibular and/or visual stimulation while traveling via transport. Surveys have shown that up to $100 \%$ of ship passengers become seasick on very rough seas (Kozarsky, 1998). Space motion sickness is experienced by $60 \%-80 \%$ of space travelers during their first 2-3 days in microgravity in spite of simulated training on the ground (Heer and Paloski, 2006). It is commonly accepted that the central nervous

This work was supported by grants from the National Natural Science Foundation of China (No. 81372131, 81071614, 81671859, and 81601639), from the Natural Science Foundation of Jiangsu Province, China (BK20161282), and by a project funding from the Priority Academic Program Development of Jiangsu Higher Education Institutions.

${ }^{3}$ L.-H.X., Y.Y., and H.-X.L. contributed equally to this work.

https://doi.org/10.1124/jpet.119.264390.

S This article has supplemental material available at jpet.aspetjournals.org. system (CNS) mechanisms are involved in the development of motion sickness, as explained by the sensory conflict theory, but the exact underlying mechanisms are still unknown (Taillemite et al., 1997; Warwick-Evans et al., 1998; Eisenman, 2009). Motion sickness is usually treated using pharmaceuticals that almost all have undesirable side effects (Herron, 2010), especially inhibitory effects on the CNS, which affect people working at sea or in space. Therefore, it is necessary to conduct further studies to elucidate the mechanisms underlying motion sickness and to find new targets for developing new preventive drugs.

Increasing evidence suggests that plasma arginine vasopressin (AVP) levels are markedly increased during motion sickness (Kim et al., 1997; Horii et al., 2001; Lien et al., 2003) and that intravenous or intracerebroventricular perfusion of AVP can cause nausea or vomiting in humans and experimental animals (Carpenter et al., 1984; Kim et al., 1997;

ABBREVIATIONS: AQP2, aquaporin 2; AVP, arginine vasopressin; CNS, central nervous systemCREB cAMP-response element binding protein; CTA, conditioned taste aversion; DDAVP, desmopressin acetateGAPDH glyceraldehyde-3-phosphate dehydrogenase; p-, phosphorylated; PCR, polymerase chain reactionPKA protein kinase A; PVN, paraventricular nucleus; qRT-PCR, real-time quantitative polymerase chain reaction; SSS, saccharin sodium solution; V2R, vasopressin receptor 2. 
Ikegaya and Matsuki, 2002; Lien et al., 2003; Liu et al., 2004; Tatewaki et al., 2005). Therefore, AVP is considered to be an etiologic hormone in the development of motion sickness (Cheung et al., 1994; Kim et al., 1997). Kim et al. (1997) considered that the central but not peripheral actions of AVP might contribute to nausea and slow wave disruption induced by circular vection. However, the exact mechanism underlying these etiologic effects of AVP in motion sickness remains unclear (Kim et al., 1997; Ikegaya and Matsuki, 2002; Lien et al., 2003). AVP is mainly synthesized by the paraventricular nucleus (PVN) and supraoptic nucleus and secreted into the blood through their nerve endings in the neurohypophysis. The results from Abe et al. (2011) and Xu et al. (2015) suggest that PVN of the hypothalamus may be involved in the induction of motion sickness by hypergravity and rotatory stimuli. Some studies suggest that there are likely polysynaptic projections from the vestibular nucleus to the PVN (Azzena et al., 1993; Markia et al., 2008). Additionally, the responses of PVN neurons induced by vestibular stimuli also suggest a pathway from the vestibular nucleus to PVN (Liu et al., 1997; Abe et al., 2011). Vestibular stimuli increased the expression of AVP in the PVN (Tighilet et al., 2009; Xu et al., 2015) and the secretion of AVP into the blood (Kim et al., 1997; Horii et al., 2001; Lien et al., 2003). Vasopressin receptor 1 in the CNS is potentially involved in the development of motion sickness (Cheung et al., 1992, 1994; Kim et al., 1997; Xu et al., 2015). However, we do not know whether vasopressin receptor 2 (V2R) in the inner ear is also involved.

Motion sickness is somewhat similar to Meniere disease in symptoms. Recent studies suggest that plasma AVP levels are greatly increased in human subjects with Meniere disease, which causes high aquaporin 2 (AQP2) expression in the inner ears, especially in the endolymphatic sacs via the V2R-AQP2 signaling pathway. Increased endolymph production leads to endolymphatic hydrops and overstimulation of the vestibular end organs, eventually resulting in various symptoms, such as vertigo, nausea, and vomiting (Takeda et al., 1995, 2003, 2010; Maekawa et al., 2010). However, it is unclear whether the AVP-V2R-AQP2 signaling pathway is also involved in the development of motion sickness. We suppose that the underlying mechanism in motion sickness may be in part similar to that in Meniere disease; i.e., abnormal vestibular and/or visual stimuli will induce AVP release from the PVN, activation of the AVP-V2R-AQP2 signaling pathway in the inner ears, and vestibular end-organ overactivity. Therefore, the present study was designed to investigate the relationship between the inner ear AVP-V2R-AQP2 signaling pathway and motion sickness to uncover inner ear-related mechanisms of motion sickness, identify new targets in this signaling pathway, and testify the anti-motion sickness effects of mozavaptan, a V2R antagonist.

\section{Materials and Methods}

Experimental Design. We investigated whether activation of the inner ear AVP-V2R-AQP2 signaling pathway is potentially involved in the development of motion sickness and whether blocking V2R is more effective in reducing motion sickness. We adopted two motion sickness models using dogs and rats, respectively, to test the anti-motion sickness effects of AVP V2R antagonist mozavaptan (OPC-31260).

Animals and Chemicals. Sprague-Dawley rats (b.wt. 200-220 g) of both genders and pregnant dams were obtained from the Experimental
Animal Center of Nantong University, Nantong, China. Six male and 14 female beagle dogs (age 8.0-8.5 months, b.wt. 7.5-8.8 kg) were purchased from Shanghai Jia-Gan Biologic Science and Technology Co., Ltd., which was qualified and certified by the Shanghai Laboratory Animal Management Committee [SCXK (Hu) 2015-0005]. An additional 12 beagle dogs (six males and six females, age 8.5-9 months, b.wt. $7.8-10.2 \mathrm{~kg}$ ) were purchased for vestibular training from Yangzhou Sifang Experimental Animal Technology Co., Ltd., which was qualified and certified by the Jiangsu Laboratory Animal Management Committee [SCXK (Su) 2008-0006]. All procedures used in this study were in accordance with our institutional guidelines, which comply with the Animal Research: Reporting of In Vivo Experiments guidelines and were approved by the Animal Care and Use Committee of Nantong University, Nantong, China.

Adult rats were fed under 12-hour light/dark cycles (light, 08:00-20: 00 hour; darkness, 20:00-08:00 hour) at room temperature $22-24^{\circ} \mathrm{C}$ with free access to standard rat chow and tap water. Beagle dogs were housed in kennels at the Experimental Animal Center of Nantong University. Dogs were fed under natural light/dark cycles at a temperature of $16-26^{\circ} \mathrm{C}$ and $40 \%-70 \%$ relative humidity with free access to tap water. Standard canine food was provided in the morning and afternoon. The dogs were under the care of a licensed veterinarian.

Common inorganic salts were purchased in China. Culture medium was purchased from Invitrogen (Carlsbad). The following primary antibodies were purchased: anti-V2R and monoclonal anti-GAPDH from Merck Millipore (Temecula); monoclonal anti- $\beta$-actin from Sigma-Aldrich (Saint Louis); anti-p-AQP2 Ser 256 from Abcam Trading (Shanghai) Company Ltd. (China); anti-AQP2 and anticytokeratin 7 from Santa Cruz Biotechnology, Inc. (Dallas); and anti-PKA C- $\alpha$, anti-p-PKA C-Thr 197, anti-CREB (48H2), and antip-CREB Ser 133 from Cell Signaling Technology (Danvers). V2R agonist desmopressin acetate (DDAVP), AVP, V2R antagonist mozavaptan (hydrochloride), poly-D-lysine, PKA inhibitor H89 dihydrochloride, cytosine $\beta$-D-arabinofuranoside, SDS, and other chemicals except those indicated elsewhere were purchased from Sigma-Aldrich.

Motion Sickness-Provoking Rotatory Stimuli and Vestibular Training. Because they lack an emetic reflex, rats do not develop the symptoms of nausea and vomiting. However, rats will produce conditioned taste aversions (CTAs) after exposure to a vestibular stimulus, which has been used as a behavioral index ("being sick") substitute for motion sickness in rats (Ossenkopp, 1983; Fox and McKenna, 1988; Sutton et al., 1988; Gallo et al., 1999; Li et al., 2005).

The rotatory stimulator for use in small animals shown in our previous study (Li et al., 2005) was manufactured according to the report by Crampton and Lucot (1985). For the induction of CTA, rats were rotated in the stimulator in alternating acceleration and deceleration modes. The acceleration rate was $16 \% \mathrm{~s}^{2}$ for 7.5 seconds with a maximal velocity of $120 \%$, and the deceleration rate was $48 \% \mathrm{~s}^{2}$ for 2.5 seconds. The clockwise and counterclockwise rotations were alternately repeated for a total time of 120 minutes. Before rotatory stimulation, in addition to tap water, the rats were also supplied with $0.15 \%$ saccharin sodium solution (SSS) as a novel fluid for drinking for 48 hours. When the rotatory stimulation was completed, a supply of $0.15 \%$ SSS was maintained for 3 days. Intake volume of $0.15 \%$ SSS per 24 hours was measured. The rats with intake volume decreases less than $10 \%$ were considered to be not susceptible to motion sickness. In contrast, the rats with intake volume decreases more than $15 \%$ were considered to be susceptible.

For the induction of motion sickness in beagle dogs, the animals were rotated in the same way as with the rats. The clockwise and counterclockwise rotations were alternately repeated until the development of the first vomiting action. Before vomiting, saliva dropping was seen commonly. Salivation and vomiting served as the indices of motion sickness in the dogs. The same rotatory test was repeated 1 week later. The latencies to salivation and vomit in the two tests were averaged as control values. The dogs with a vomit latency of 5-15 minutes were selected for further drug tests and vestibular training. 
To perform the vestibular training, rats susceptible to motion sickness identified after the above motion sickness-provoking rotatory stimulus (provoking test) were rotated once a day in the same way with the duration gradually increased from 10 to 60 minutes over a month (10-minute increase per 5 days). For vestibular training with the dogs, eight susceptible dogs were rotated similarly to the rats once every 2 days for 3 months, and the rotation duration was increased from 4 to 12 minutes with a 2-minute increase every 2 weeks.

At 1 week after the end of the vestibular training, the animals were tested with the provoking test, and loss of CTA in the rat or a significant extension of the vomit latency in the dog was considered to be an acquisition of an adaption against this provoking test.

Drug Tests in the Dogs and Rats for Motion Sickness Induced by Rotatory Stimuli. For drug tests on motion sickness in the dogs, 12 susceptible dogs were selected from 20 dogs, and a $6 \times 6$ Latin square design was used with one test every week. For example, 12 dogs were randomly allocated to six groups, including the control group; groups receiving 0.018 and $0.036 \mathrm{mg} / \mathrm{kg}$ scopolamine (a positive control drug for anti-motion sickness); and groups receiving 0.9, 1.8, and $3.6 \mathrm{mg} / \mathrm{kg}$ mozavaptan (an antagonist of $\mathrm{V} 2 \mathrm{R}$ ), with a total observation time of 6 weeks. Rotatory stimulus was performed as described above for 30 minutes or until vomiting was induced. The drugs were orally administered 1 hour before the rotatory stimulus, and control dogs were given an equal volume of solvent $(0.2 \mathrm{ml} / \mathrm{kg}$ normal saline).

To investigate whether the AVP V2R agonist promotes the induction of motion sickness due to rotatory stimulus in the dogs, 15 beagle dogs were selected from 20 dogs and allocated to two groups with vomiting latencies less or more than 10 minutes. In the following 3 weeks, each dog randomly received one treatment of control or 0.25 or $0.5 \mu \mathrm{g} / \mathrm{kg}$ DDAVP each week. Rotatory stimulus was described as above for 30 minutes or until vomiting was induced. The V2R agonist DDAVP was injected intramuscularly 1 hour before the rotatory stimulus, and control dogs were given an equal volume of solvent $(0.1 \mathrm{ml} / \mathrm{kg}$ normal saline).

For the drug tests on motion sickness in rats, susceptible rats were randomly allocated to three groups, including the control group and groups receiving 2.5 and $5.0 \mathrm{mg} / \mathrm{kg}$ mozavaptan. Mozavaptan was delivered via intraperitoneal injection 45 minutes before 2 hours of rotatory stimulus, and the control rats received an equal injection volume of solvent ( $2 \mathrm{ml} / \mathrm{kg}$ normal saline).

CTA Induction in the Rats via Intraperitoneal Injection of AVP and V2R Agonist and Inhibition by V2R Antagonist. To induce CTA in rats, AVP was intraperitoneally injected at doses of 100,200 , and $400 \mu \mathrm{g} / \mathrm{kg}$. In addition to drinking water, $0.15 \% \mathrm{SSS}$ was also supplied at the same time for the rats to drink for 2 days before AVP injection and 2 days after AVP injection. The mean intake volume of $0.15 \%$ SSS before and after AVP injection was measured. To further investigate whether the induction of CTA by AVP in rats is mediated by V2R, a V2R agonist, DDAVP $(0.45$ and $0.9 \mu \mathrm{g} / \mathrm{kg}$, i.p. $)$, was used to see whether it could also induce CTA. Similarly, the reduction in $0.15 \%$ SSS intake volume was measured after DDAVP injection.

Additionally, an antagonist of V2R, mozavaptan, was used to determine whether it could block the CTA-inductive effects of DDAVP. Mozavaptan was intraperitoneally injected at doses of 3.2 and $6.4 \mathrm{mg} / \mathrm{kg}$. Control rats were injected intraperitoneally with an equal volume of solvent ( $2 \mathrm{ml} / \mathrm{kg}$ normal saline).

Middle Ear Injection through the Tympanic Membrane. Middle ear injection of drugs through the tympanic membrane (intratympanic injection) was performed under ether anesthesia according to previous reports (Hunt et al., 1987; Takumida and Anniko, 2006; Liu et al., 2016; Zou and Pyykko, 2016). Rats were placed on a heating pad in a prone position, the tympanic membrane was penetrated under an operating microscope at the upper edge of the posterior upper quadrant with a 30 -gauge needle, and a total of $50 \mu \mathrm{l}$ of drug solution for each side was respectively injected into both middle ear cavities. The animals received subsequent treatments 2 hours after the injections.
Epithelial Cell Culture of the Endolymphatic Sacs. Epithelial cell culture of the endolymphatic sacs was conducted based on other reports (Dahlmann and von During, 1995; Agrup et al., 2001; Kumagami et al., 2009). Rat pups at 10 days after birth were used for primary culture of the endolymphatic sac epithelial cells. After ether anesthesia, the temporal bones from both sides were removed and placed in a cold $\left(4^{\circ} \mathrm{C}\right)$ endolymph-like solution containing $150 \mathrm{mM} \mathrm{KCl}$, $5 \mathrm{mM} \mathrm{NaCl}, 2 \mathrm{mM} \mathrm{KH} \mathrm{KO}_{4}, 1 \mathrm{mM} \mathrm{MgCl} 2,3 \mathrm{mM}$ glucose, $25 \mathrm{mM}$ HEPES, and $1 \mathrm{mg} / \mathrm{ml}$ of albumin. The endolymphatic sacs were carefully isolated with the aid of a dissecting microscope. The endolymphatic sacs were divided into small pieces, transferred to culture dishes, and attached as explants to poly-lysine-coated cover slips with the gentle pressure of a scalpel. The explants were cultured for 5 days at $37^{\circ} \mathrm{C}$ in a humidified $5 \% \mathrm{CO}_{2}$ incubator. The culture medium used was Dulbecco's modified Eagle's medium with the addition of $15 \%$ fetal calf serum, penicillin ( $85 \mathrm{IU} / \mathrm{ml})$, streptomycin $(85 \mu \mathrm{g} / \mathrm{ml})$, and epithelial growth factor $(100 \mu \mathrm{g} / \mathrm{ml})$. Half of the culture medium was changed every 3 days. On day 6 in vitro, the explants were digested with $0.125 \%$ trypsin, dispersed gently with a heatpolished pipette, and then cultured with the above culture medium containing Bromodeoxyuridine $(0.1 \mathrm{mM})$. On day 11 in vitro, the cultures were digested once more with $0.125 \%$ trypsin containing EDTA $4 \mathrm{Na}(190 \mathrm{mg} / \mathrm{l}$; Gibco, Shanghai, China) and centrifuged at $1500 \mathrm{rpm}$ for 4 minutes. The supernatants were discarded, and the cells were resuspended with the above culture medium and seeded on poly-lysine-coated cover slips or culture dishes. On days 15-16 in vitro, the cultured epithelial cells from the endolymphatic sac were used for the following experiments. The cultured cells were identified via the immunofluorescent observation of the following characteristic markers: 1) cytokeratin-7 (a maker of epithelial cells), 2) AQP2, and 3) V2R (Supplemental Fig. 1). A purity of $>90 \%$ for the cultured epithelial cells from the endolymphatic sacs was obtained.

Real-Time Quantitative Polymerase Chain Reaction. Rats were decapitated under $10 \%$ chloral hydrate anesthesia $(400 \mathrm{mg} / \mathrm{kg}$, i.p.), the temporal bones from both sides were removed and placed in cold $\left(4^{\circ} \mathrm{C}\right) \mathrm{PBS}(0.1 \mathrm{M}, \mathrm{pH} 7.4)$, and the inner ears and endolymphatic sacs were isolated under a dissecting microscope. The inner ears and endolymphatic sacs or the cultured epithelial cells from the endolymphatic sacs were homogenized in Trizol reagent (Invitrogen), and total RNA was purified. Potential DNA contamination was removed using DNase and, $1 \mu \mathrm{g}$ RNA was used for first-strand cDNA synthesis by retrotranscription using oligo(dT) primers and the PrimeScript RT Reagent Kit (Tiangen Biotech Co., Ltd, Beijing, China) according to the manufacturer's instructions. Real-time quantitative polymerase chain reaction (qRT-PCR) was performed in a Rotor-Gene PCR machine (RG-3000A; Corbett Research Proprietary Limited, New South Wales, Australia), and the detailed cycling conditions were as follows: 1) an initial denaturation step at $95^{\circ} \mathrm{C}$ for 5 seconds and 2) 45 cycles of a $95^{\circ} \mathrm{C}$ denaturation for 15 seconds, $55^{\circ} \mathrm{C}$ annealing for 30 seconds, and $72^{\circ} \mathrm{C}$ extension for 20 seconds. The amount of cDNA per sample was determined using a SYBR Premix Ex Taq kit (Roche, Basel, Switzerland). PCR reaction progression was assessed by changes in the SYBR green dye fluorescence (Roche) attached to the double-stranded DNA. All values were normalized to the housekeeping gene $\beta$-actin or GAPDH. The following primer pairs were used for qRT-PCR: 1) AQP2, forward, 5'-TGAGTTCTTGGCCACGCTCCTTT$3^{\prime}$, and reverse, 5'-ATGGAGAGGGCAGGGCTACC-3' and 2) V2R, forward, 5'-GCCACTGACCGCTTCCAT-3', and reverse, 5' -CACCCC ACTGCCATTTCC-3'.

Western Blot Analysis. The inner ears and endolymphatic sacs isolated from the rat temporal bones or the cultured epithelial cells from the endolymphatic sacs were lysed in tissue or cell lysis buffer containing phenylmethanesulfonyl fluoride (Beyotime, Nantong, China), homogenized, and then centrifuged at $14,000 \mathrm{rpm}$ for 20 minutes at $4^{\circ} \mathrm{C}$. The protein contents of the supernatants were determined spectrophotometrically using the bicinchoninic acid method. Equal amounts of protein ( $40 \mu \mathrm{g}$ per lane) from each sample were loaded on a $10 \%$ SDS-PAGE, electrophoresed, and transferred 
onto polyvinyledene difluoride membranes (Merck Millipore). These membranes were blocked in 5\% nonfat milk in Tris-buffered saline containing $0.1 \%$ Tween- 20 for 2 hours at room temperature and then incubated overnight at $4^{\circ} \mathrm{C}$ with the primary antibodies against AQP2 (1:100), p-AQP2 (1:300), CREB (1:1000), p-CREB (1:1000), PKA (1: $1000)$, p-PKA (1:1000), V2R (1:100), $\beta$-actin (1:5000), or GAPDH (1: 5000 ). Finally, the membranes were incubated with a second antibody (1:6000; Bioworld, Nanjing, China) conjugated with horseradish peroxidase for 2 hours at room temperature, and the immunoreactive bands were visualized by enhanced chemiluminescent agents (Pierce Biotechnology, Rockford) and captured using a Tanon 5200 multi system (Tanon, Shanghai, China). Expression level of each protein was quantified using Image-J analysis software and normalized to the $\beta$-actin, CREB, or GAPDH value in the same lane. The same samples were repeatedly analyzed at least two times.

Immunofluorescent Observations. Rats were anesthetized with $10 \%$ chloral hydrate $(400 \mathrm{mg} / \mathrm{kg}$, i.p.) and perfused transcardially with $200 \mathrm{ml}$ of normal saline containing sodium heparin (2000 IU) and subsequently $500 \mathrm{ml}$ of $4 \%$ paraformaldehyde in PBS (0.1 M, pH 7.4). The temporal bones were then isolated, postfixed in $4 \%$ paraformaldehyde for 12 hours, and immersed in decalcification solution containing $0.2 \mathrm{M}$ EDTA- $\mathrm{Na}_{2}$ at $37^{\circ} \mathrm{C}$ for 28 days. After dehydration with ethanol, the tissues were embedded in paraffin. Paraffinembedded tissues were then sectioned at $5-\mu \mathrm{m}$ thickness and mounted
A

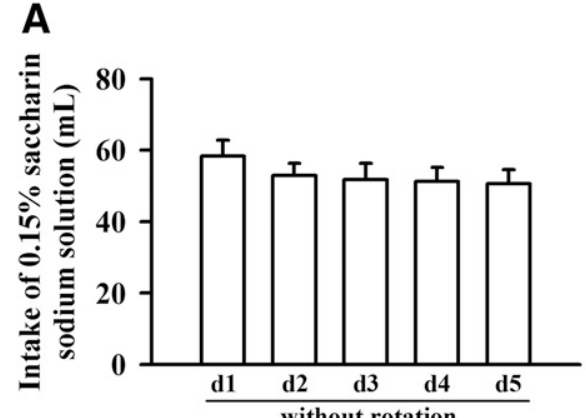

D
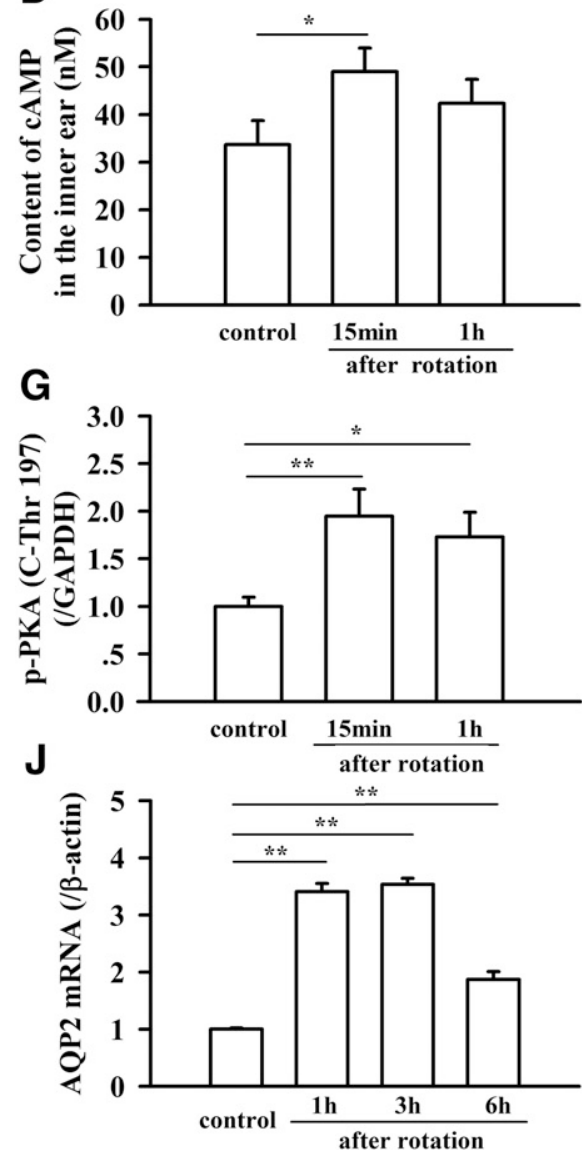

B

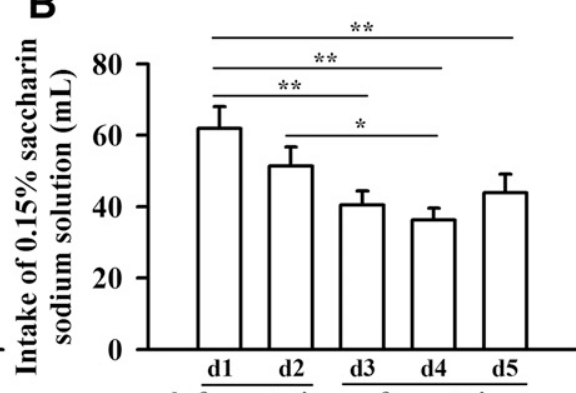

E

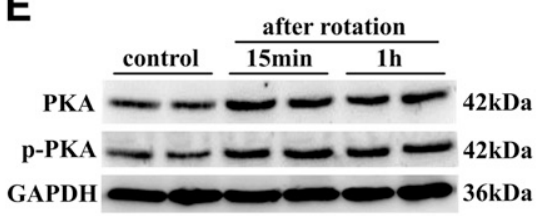

H
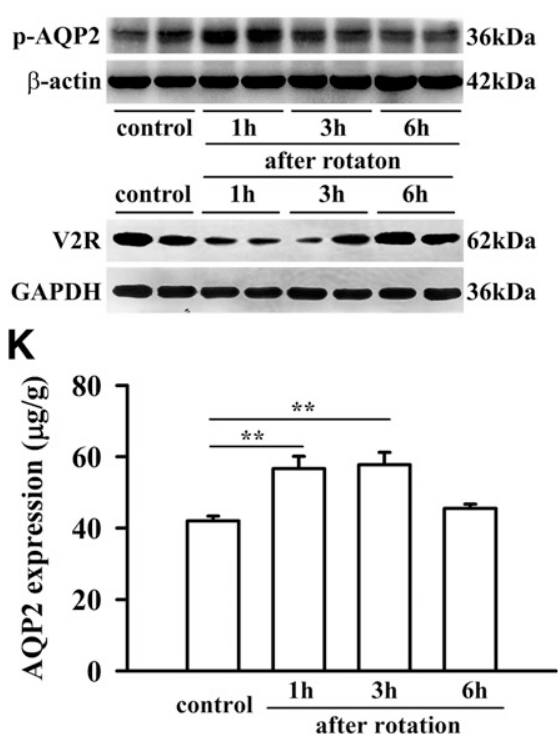

C

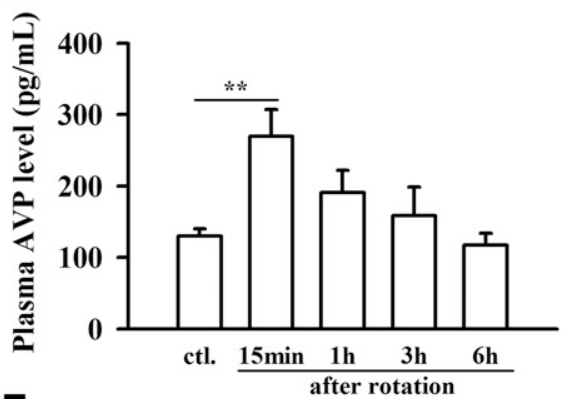

$\mathbf{F}$

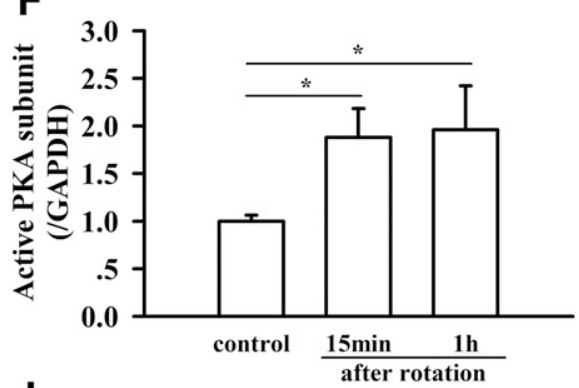

I
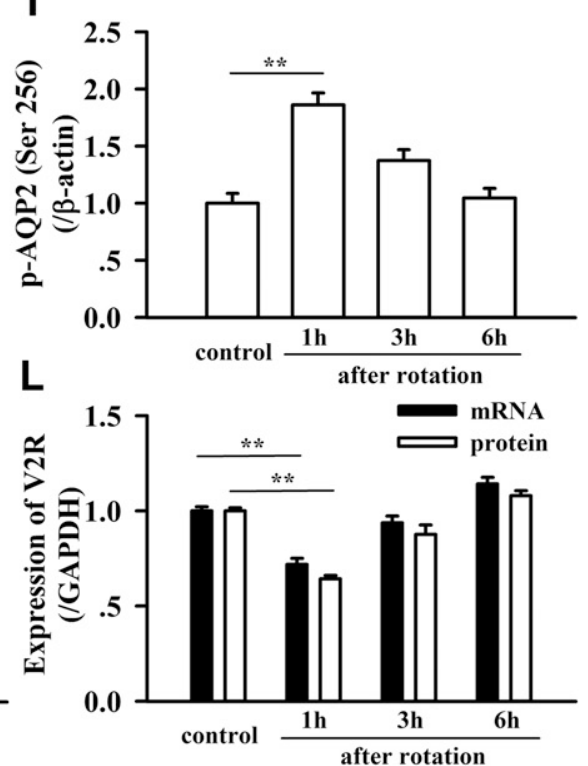

Fig. 1. Induction of CTA, elevated plasma AVP levels, and activation of the V2R-AQP2 pathway in rat inner ear after rotatory stimulus. (A) Intake of $0.15 \%$ saccharin solution over five consecutive days by control rats without rotatory stimulus $(n=12)$. (B) Intake of $0.15 \%$ saccharin solution by rats before and after rotatory stimulus $(n=12)$. (C) Changes in plasma AVP levels $(n=12)$. (D) Changes in cAMP contents $(n=8)$. (E) Western blot analysis for active PKA subunit and p-PKA. (F and G) Mean values for active PKA and p-PKA expression $(n=8)$. (H) Western blot analysis for p-AQP2 and V2R. (I) Mean values for p-AQP2 expression $(n=8)$. (J) Mean values for AQP2 mRNA levels measured by qRT-PCR $(n=8)$. (K) Mean values for AQP2 expression measured by ELISA $(n=8)$. (L) Changes in V2R mRNA expression measured by qRT-PCR $(n=8)$ and V2R protein measured by Western blot analysis $(n=8)$. $* P<0.05 ; * * P<0.01$. ctl., control. 
on slides. Prior to immunostaining, selected paraffin sections were dewaxed using xylenes. The sections were quenched in a $3 \%$ hydrogen peroxide methanol solution, pretreated to promote antigen retrieval through steaming with citrate buffer solution $\left(\mathrm{pH} 6.0,95^{\circ} \mathrm{C}\right)$, and incubated with 5\% normal goat serum for 1 hour and then with primary antibodies at different dilutions overnight at $4^{\circ} \mathrm{C}$. The cultured epithelial cells from the endolymphatic sacs were fixed with 4\% paraformaldehyde at room temperature for 15 minutes and then incubated with precooled methanol at $-20^{\circ} \mathrm{C}$ for 8 minutes. After incubation with $10 \%$ bull serum albumin for 1 hour, the cells were incubated with primary antibodies at different dilutions overnight at $4^{\circ} \mathrm{C}$. Simultaneously, a negative control was performed without each primary antibody. For immunofluorescent observation of the target molecule distribution in the inner ears or their expression in cultured endolymphatic sac epithelial cells, tissue sections or cultured cells were incubated with donkey anti-rabbit Alexa-488, donkey anti-mouse Alexa-594, or donkey anti-rabbit Alexa-647 secondary antibodies (1: 1000; Jackson, West Grove) for 1-2 hours at room temperature. The immunostained images were collected using a laser confocal microscope (TCS SP8; Leica Microsystems, Wetzlar, Germany) at room temperature and processed with the software LASX 2.0.

ELISA. Blood was obtained within 30 minutes after the end of rotatory stimulus from the cephalic vein of the anterior legs of dogs and at different times after rotation from the left ventricle of rats under $10 \%$ chloral hydrate anesthesia $(400 \mathrm{mg} / \mathrm{kg}$, i.p.). Blood samples ( $2 \mathrm{ml}$ of each) from rats and dogs were all placed in test tubes containing $200 \mu \mathrm{g}$ of dried sodium heparin, shaken gently, and centrifuged at $4000 \mathrm{rpm}$ at $4^{\circ} \mathrm{C}$ for 5 minutes. The inner ears and endolymphatic sacs were isolated from the rat temporal bones under a dissecting microscope and homogenized in tissue lysis buffer $\left(4^{\circ} \mathrm{C}\right)$. The cultured endolymphatic sac epithelial cells were isolated and homogenized in $0.1 \mathrm{M}$ of $\mathrm{HCl} / \mathrm{cell}$ lysis buffer $\left(1: 5,4^{\circ} \mathrm{C}\right)$. The homogenized tissues or cells were centrifuged at $4^{\circ} \mathrm{C}$ and $14,000 \mathrm{rpm}$ for 15 minutes. The supernatants were then collected. All of these samples were frozen and stored at $-80^{\circ} \mathrm{C}$ for subsequent analyses. The AVP, cAMP, and AQP2 contents were assayed in duplicate using an AVP assay kit (R\&D Systems, Minneapolis), a cAMP assay kit (R\&D Systems), and an AQP2 assay kit (CUSABIO, Baltimore), respectively, according to the manufacturers' guidelines.

Statistical Analysis. All data are presented as the mean \pm S.E.M. After the homogeneity of variance test, Student's $t$ test was used for the comparison of two groups, two-way ANOVA was used for the comparison of data from Latin design experiments, and one-way ANOVA was used for the comparison of data from the other expreiments with three or more groups, with the least significant difference test for post hoc comparisons between two groups. Differences were considered statistically significant at a level of $P<0.05$.

\section{Results}

Rotatory Stimuli Induce CTA and Increase Plasma AVP Levels in Rats and Change V2R-AQP2 Pathway Signaling in the Inner Ear. The intake of $0.15 \%$ saccharin sodium solution was not changed in rats over 5 days without rotatory stimulus (Fig. 1A) but decreased in rats in the 3 days after rotation (Fig. 1B). Plasma AVP levels were immediately elevated after rotation and then gradually recovered to basal levels in 6 hours (Fig. 1C). Meanwhile, the cAMP contents at 15 minutes after rotation and the levels of active PKA subunit (PKA C- $\alpha$ ) and phosphorylated PKA (p-PKA C-Thr 197) 1 hour after rotation increased in the inner ears (Fig. 1, D-G). Phosphorylated AQP2 (p-AQP2 Ser 256) levels were elevated at 1 hour after rotation (Fig. 1, H and I), whereas at the same time, AQP2 expression increased and was sustained for 3 hours after rotation (Fig. 1, J and $\mathrm{K}$ ). However, the expression of vasopressin V2R was temporarily reduced 1 hour after rotation (Fig. 1L).

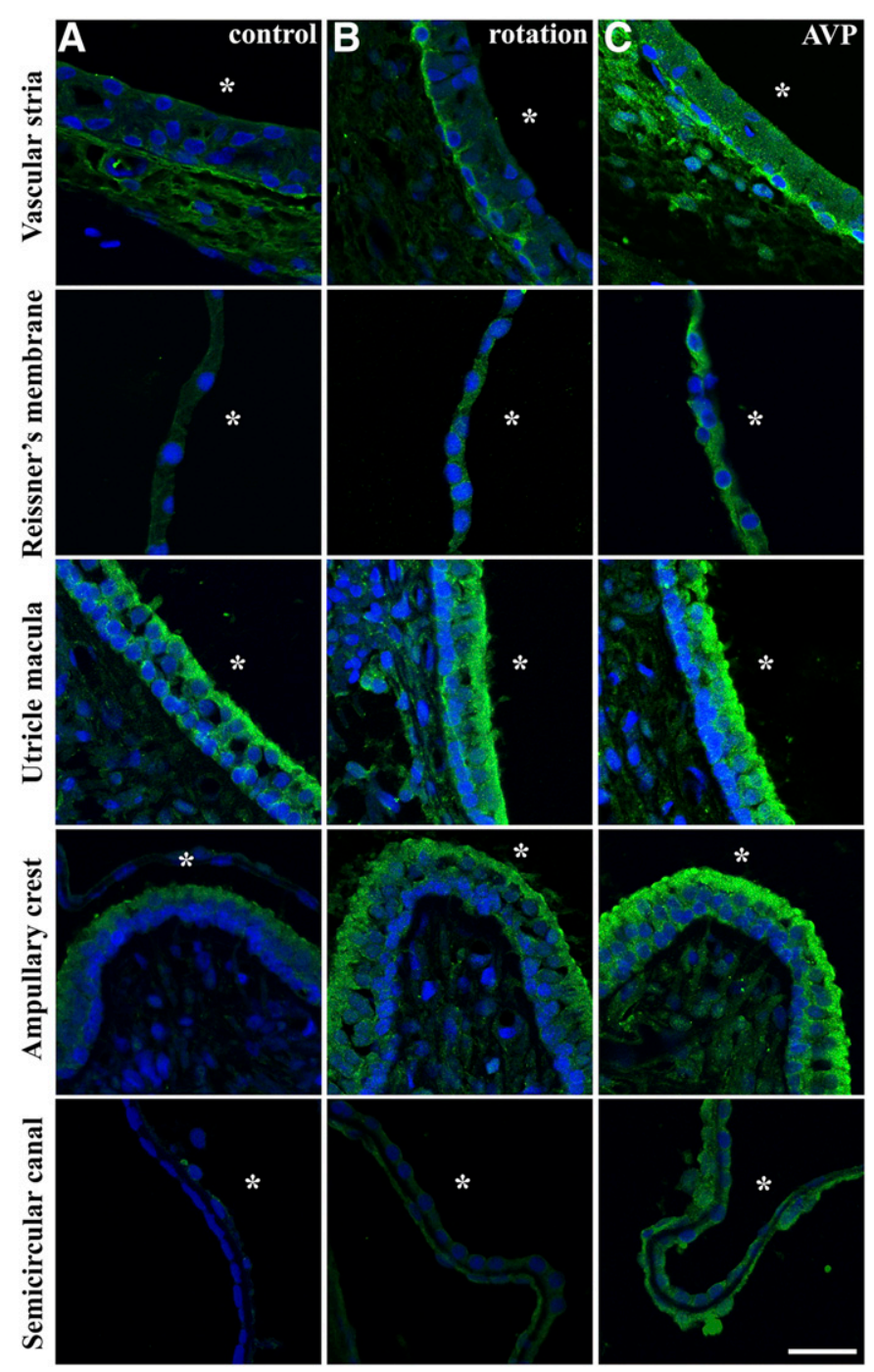

Fig. 2. AQP2 distribution in rat inner ear structures and changes after rotatory stimulus and systemic AVP treatment. (A) A control rat. (B) A rat after rotatory stimulus. (C) A rat after systemic AVP treatment. *, indication of the endolymph side. Blue, DAPI; Green, AQP2. Scale bar, 25 $\mu \mathrm{m}$.

Immunofluorescent staining revealed that AQP2 was distributed in the rat inner ear structures with stronger expression in the basolateral membrane of basal cells of the vascular stria and in the hair cells of the utricle macula and ampullary crest (Fig. 2A). The expression of AQP2 in Reissner's membrane and the semicircular canal was much weaker and disperse (Fig. 2A). AQP2 expression in these structures was elevated 1 hour after rotatory stimulus in the rats (Fig. 2B).

Intraperitoneal Injection of AVP also Induces CTA in the Rats and Changes V2R-AQP2 Pathway Signaling in the Inner Ear. As shown in Fig. 3A, intraperitoneal injection of AVP dose dependently induced a reduction of $0.15 \%$ SSS intake, indicating that CTA could be evoked by AVP. After AVP injection, the cAMP contents in rat inner ears were elevated after 15 minutes (Fig. 3B), and the levels of PKA C- $\alpha$ and p-PKA C-Thr 197 were also increased in 1 hour (Fig. 3, C-E). The p-AQP2 Ser 256 and AQP2 levels were also elevated after AVP injection (Fig. 3, F-J). The increase in the levels of p-AQP2 and AQP2 was most prominent at 1 hour after AVP 
A
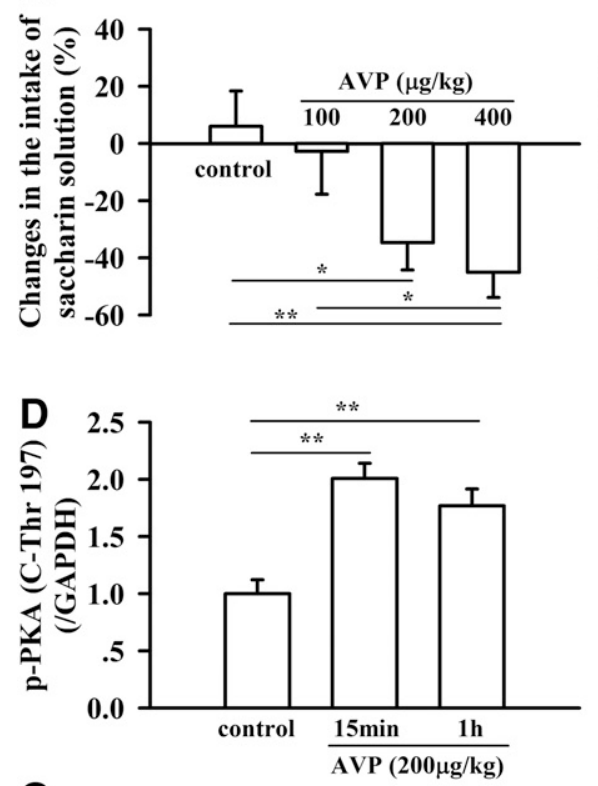

G

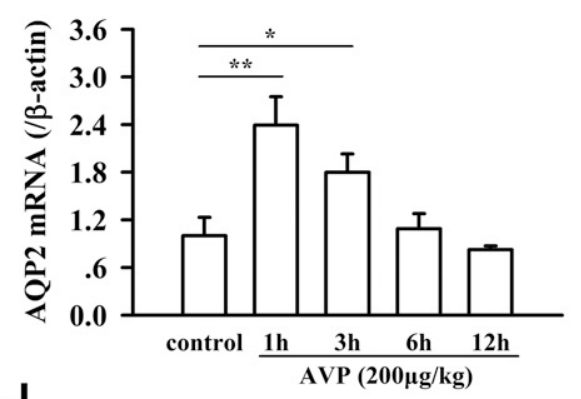

J

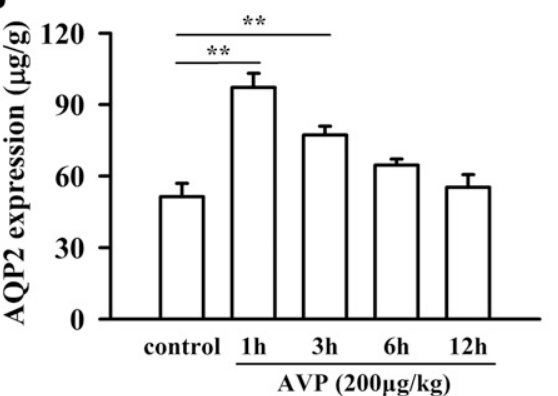

B

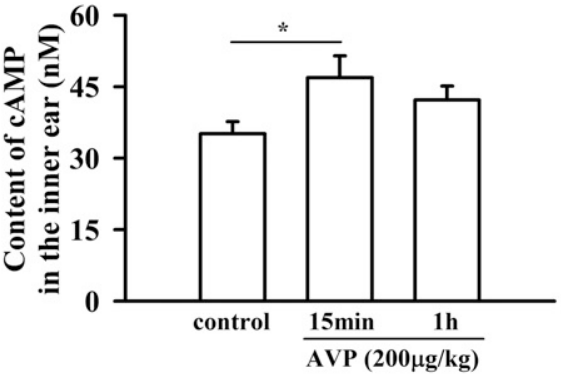

E

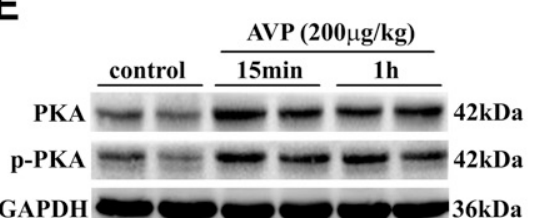

H

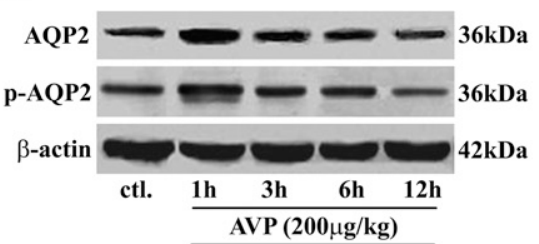

clt. $\begin{array}{llll}1 \mathrm{~h} & 3 \mathrm{~h} & 6 \mathrm{~h} & 12 \mathrm{~h}\end{array}$
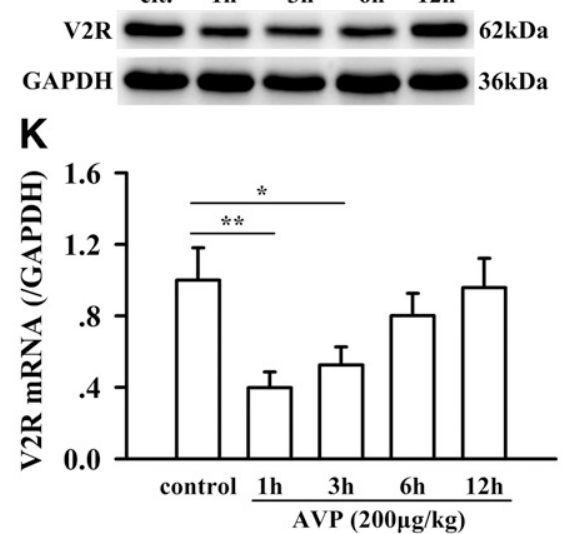
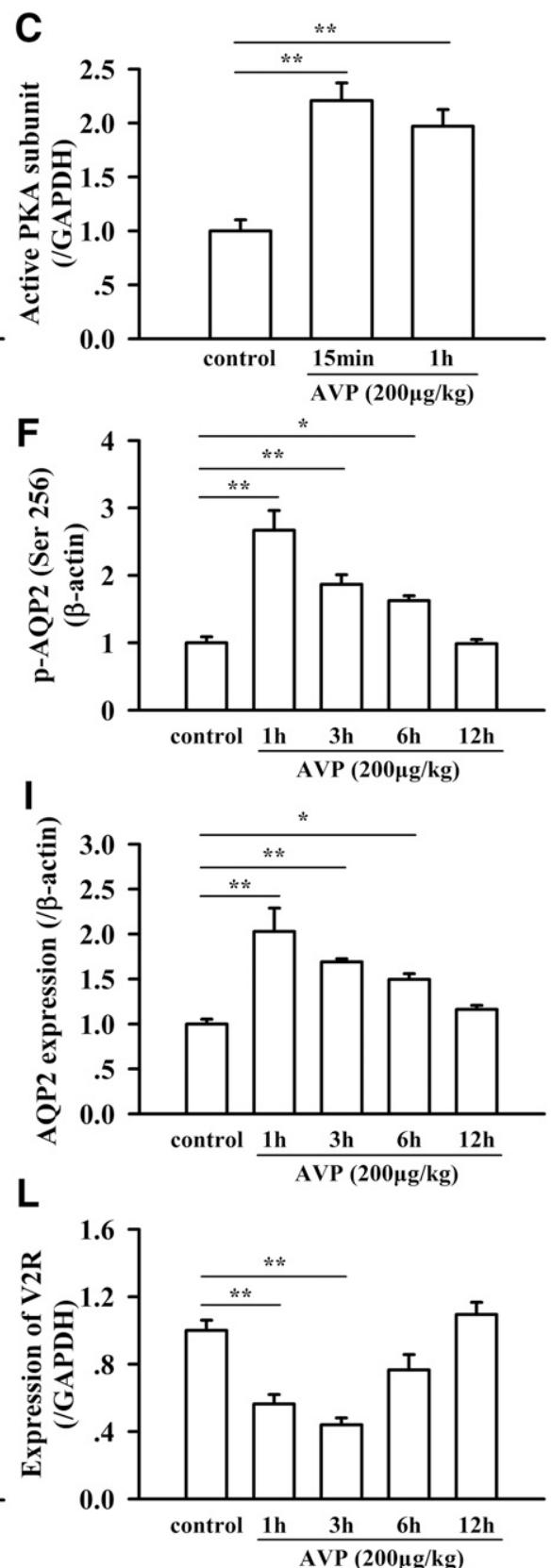

Fig. 3. Induction of CTA in the rats and changes in V2R-AQP2 signaling in the inner ear after systemic AVP treatment. (A) Intake of $0.15 \%$ saccharin solution by the rats before and after AVP treatment $(n=12)$. (B) Changes in cAMP contents $(n=8)$. (C and D) Mean values for active PKA and p-PKA expression $(n=8)$. (E) Western blot analysis for active PKA and p-PKA. (F) Mean values for p-AQP2 expression $(n=8)$. (G) Mean values for AQP2 mRNA levels measured by qRT-PCR $(n=8)$. (H) Western blot analysis for p-AQP2, AQP2, and V2R. (I and J) Mean values for AQP2 expression measured by Western blot analysis and ELISA, respectively $(n=8)$. (K and L) Mean values for V2R expression measured by qRT-PCR and Western blot analysis, respectively $(n=8) . * P<0.05 ; * * P<0.01$. ctl., control.

injection, and both of them gradually recovered to control levels within 6-12 hours after AVP treatment. However, the expression of vasopressin V2R was reactively downregulated at 1-3 hours after AVP injection (Fig. 3, H, K, and L). Immunofluorescent observations revealed that AQP2 expression in the inner ear structures, including the vascular stria, utricle macula, ampullary crest, Reissner's membrane, and semicircular canal, was markedly elevated 1 hour after the systemic treatment of rats with AVP (Fig. 2C).

AVP Perfusion Changes V2R-AQP2 Pathway Signaling in Cultured Epithelial Cells from Rat
Endolymphatic Sacs. Similar to the results obtained in the in vivo experiments after AVP injection, in vitro treatment of cultured epithelial cells from rat endolymphatic sacs with AVP also induced increases in PKA C- $\alpha$, p-AQP2 Ser 256, AQP2, and p-CREB Ser 133 levels (Fig. 4, A-H), whereas the expression of V2R was reactively downregulated 1-3 hours after AVP treatment (Fig. 4I). Immunofluorescent observations 1 hour after AVP treatment also showed an increase in PKA C$\alpha$, p-AQP2 Ser 256, and AQP2 levels; and high nuclear expression of p-CREB Ser 133 and membrane redistribution of AQP2 were also evident (Fig. 4J). 
A

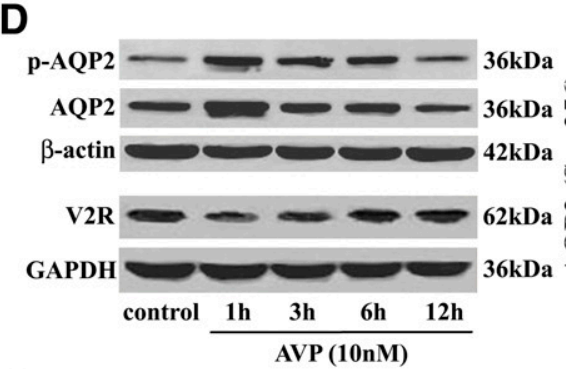

G

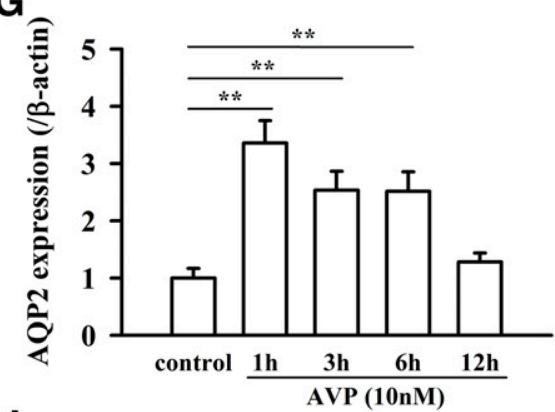

B

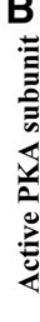

E
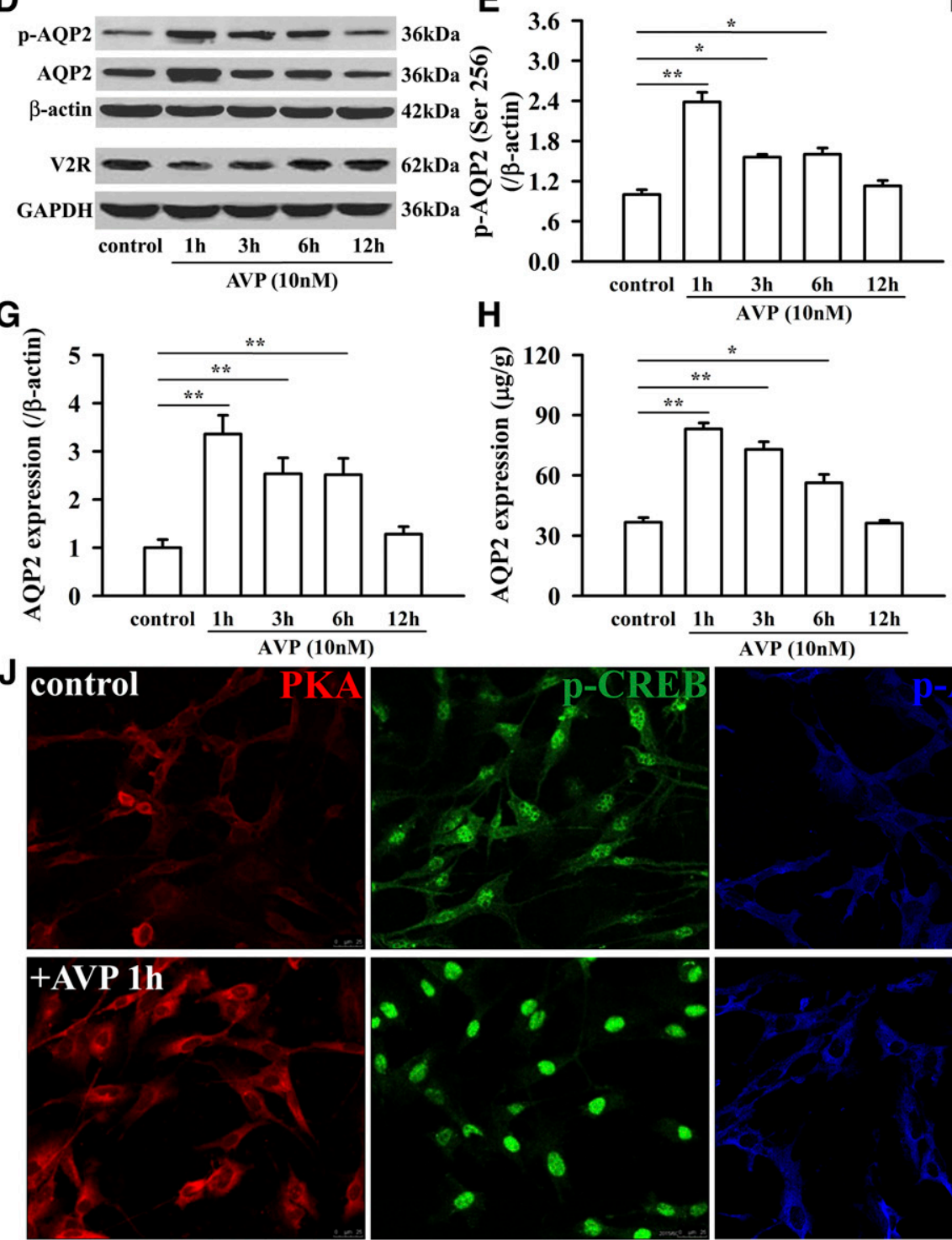

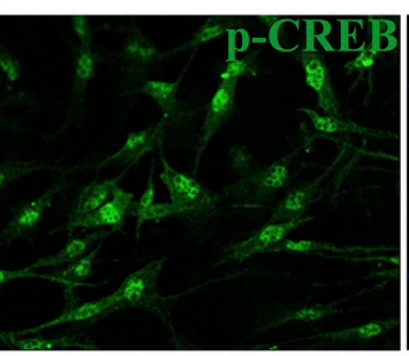

$$
\text { AVP (10nM) }
$$
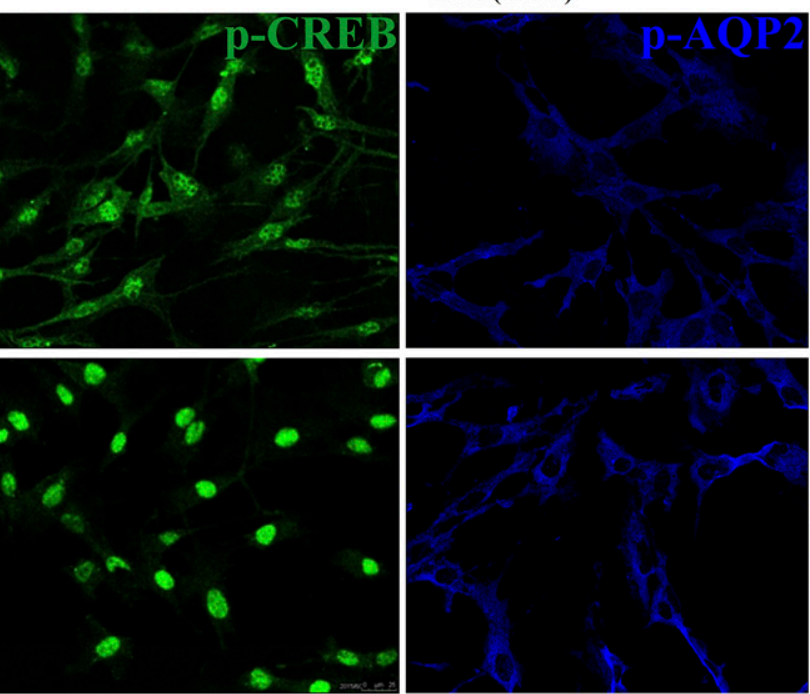

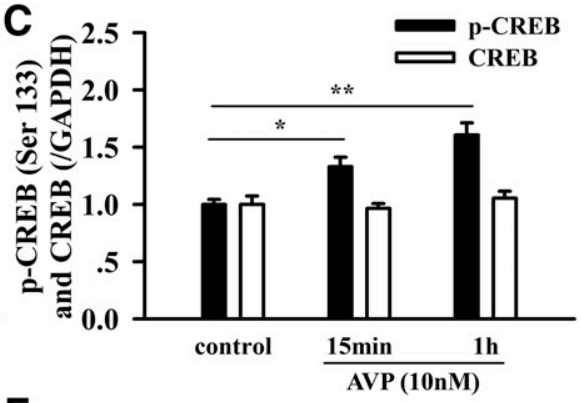

$\mathbf{F}$
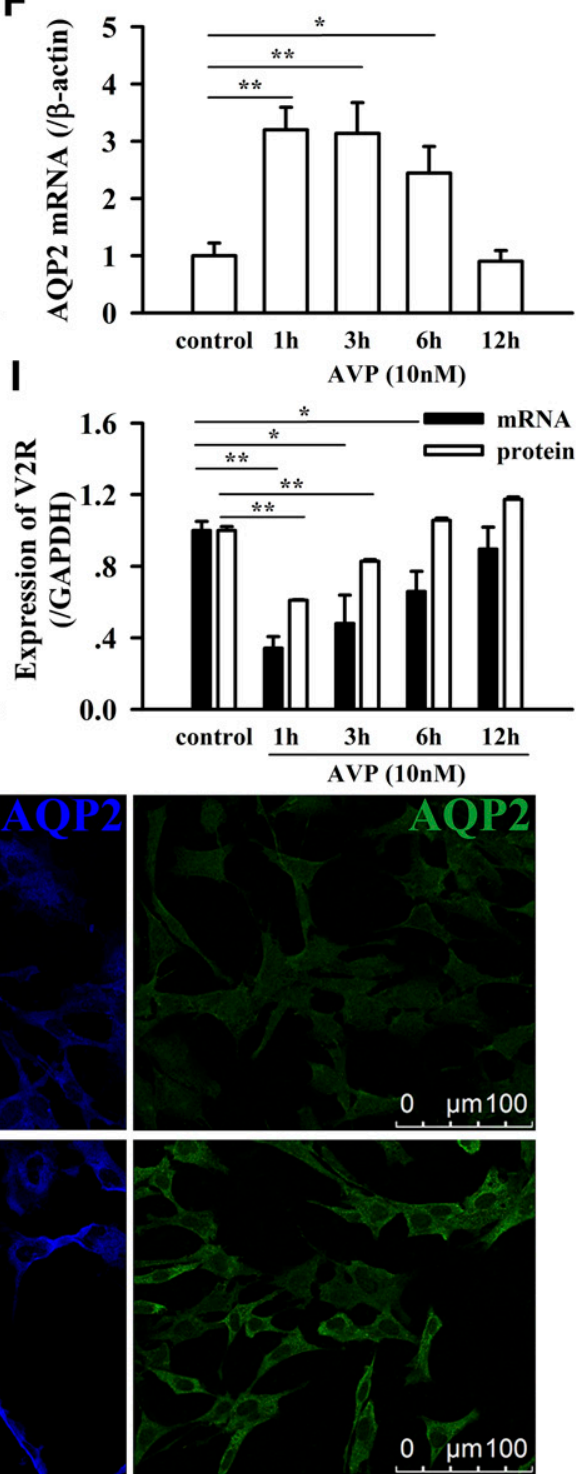

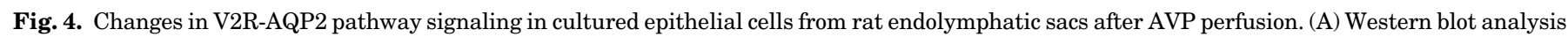

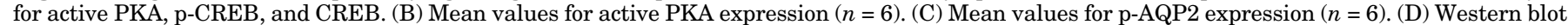

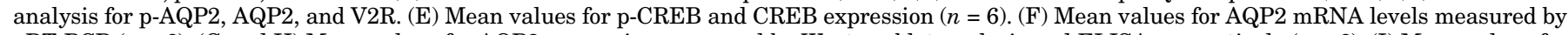

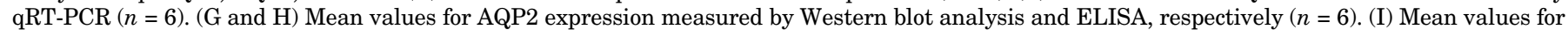

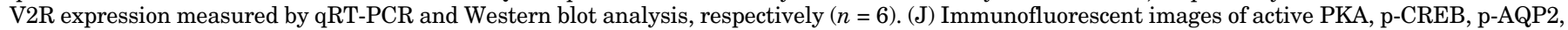
and AQP2 expression in cultured epithelial cells from rat endolymphatic sacs with or without 1 hour of AVP perfusion. $* P<0.05 ; * * P<0.01$.

Vestibular Training Reduces Changes in V2R-AQP2 Pathway Signaling in the Inner Ear and Inhibits CTA in Rats after Rotatory Stimulus. Amelioration of conditioned taste aversion was revealed by an increase in the intake of $0.15 \% \mathrm{SSS}$ after rotatory stimulus in trained rats compared with untrained rats (Fig. 5A). Meanwhile, the initial rotatory stimulus-induced increase in the expression of p-AQP2 Ser 256, AQP2, and p-CREB Ser 133 (Fig. 5, B-F) and decrease in the expression of V2R (Fig. 5, G-I) in untrained rats were remarkably blunted in the trained rats. 
A

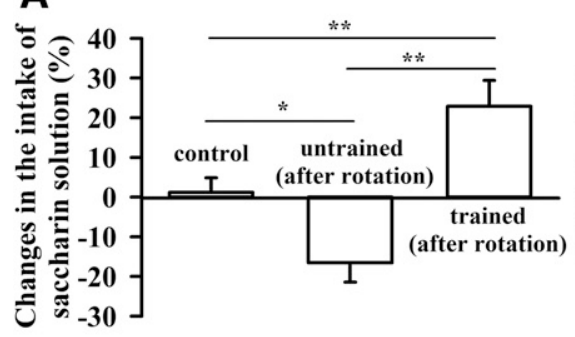

D

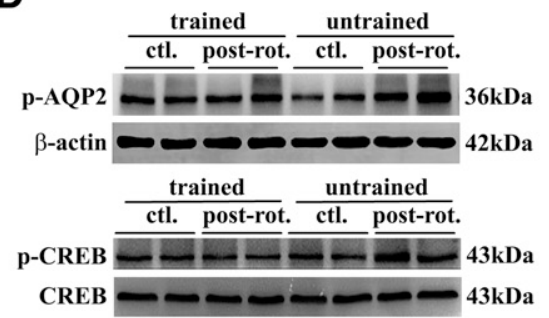

G

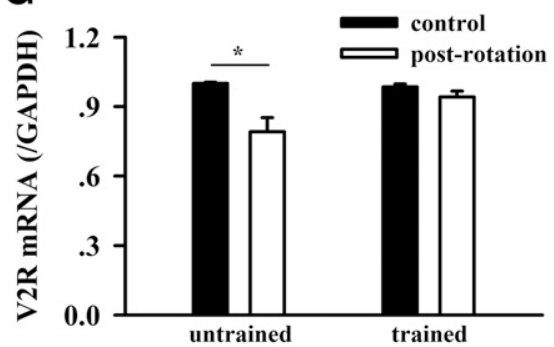

B
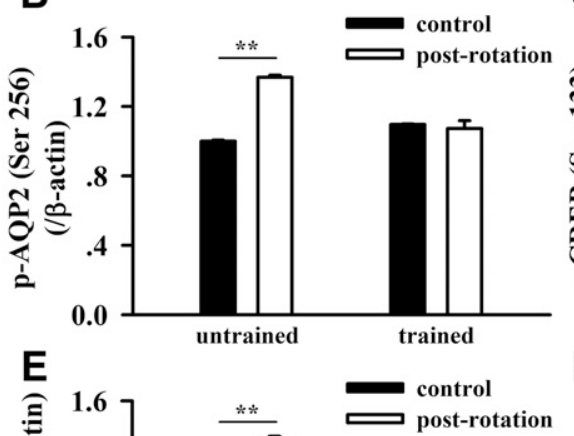

H

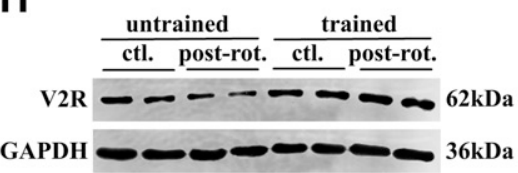

C

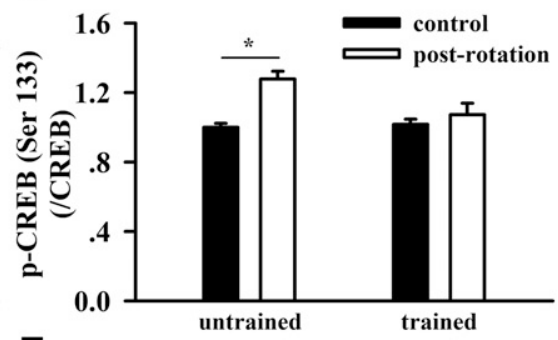

$\mathbf{F}$

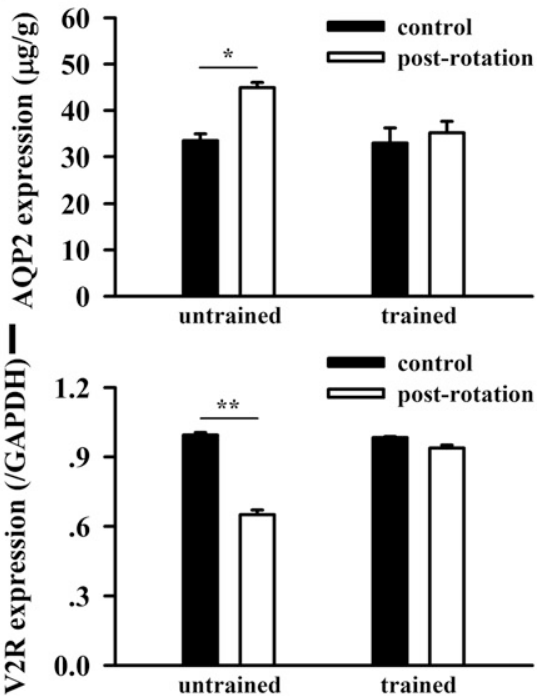

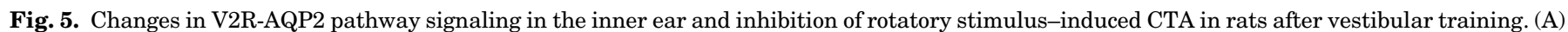

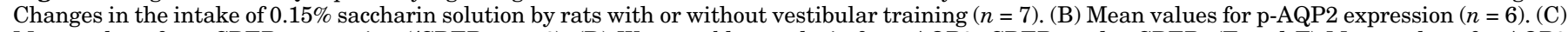

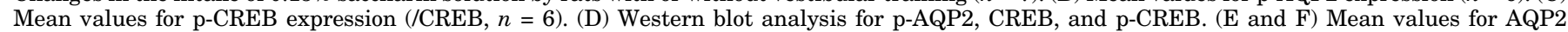

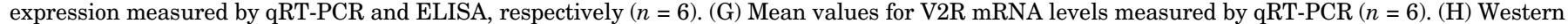
blot analysis for V2R. (I) Mean values for V2R expression $(n=6)$. $* P<0.05$; $* *<<0.01$. ctl., control; post-rot., postrotation.

Mozavaptan Blunts Changes in V2R-AQP2 Pathway Signaling in the Inner Ear and Inhibits CTA in Rats after Rotatory Stimulus. Similar to vestibular training, when the rats were pretreated with the V2R antagonist mozavaptan, conditioned taste aversion was also ameliorated by an increase in the intake of $0.15 \%$ SSS after rotatory stimulus compared with vehicle rats (Fig. 6A). Moreover, the initial rotatory stimulus-induced increase in cAMP, PKA C- $\alpha$, p-AQP2 Ser 256, AQP2, and p-CREB Ser 133 levels was significantly reduced after mozavaptan pretreatment (Fig. 6, B-I).

Mozavaptan Blunts Changes in V2R-AQP2 Pathway Signaling in Cultured Epithelial Cells from Rat Endolymphatic Sacs after AVP Perfusion. Identical to the in vivo experiments using the V2R antagonist in the rotatory test, when cultured epithelial cells from rat endolymphatic sacs were pretreated with the V2R antagonist mozavaptan, the AVP-induced increase in cAMP, PKA C- $\alpha$, p-AQP2 Ser 256, AQP2, and p-CREB Ser 133 levels (Fig. 7, A-G) and the reactive decrease in the expression of V2R (Fig. $7 \mathrm{H})$ were all blunted, whereas mozavaptan itself did not obviously influence these variables (Fig. 7, A-H).

PKA Inhibitor Blunts the Influence of AVP on p-CREB, AQP2, and p-AQP2 in Cultured Epithelial Cells from Rat Endolymphatic Sacs. To identify whether the effects of rotatory stimuli and AVP on the variables in the V2R-AQP2 signaling pathway were mediated by PKA, we used the PKA inhibitor H89. H89 dose dependently blunted AVP-induced increases in AQP2 expression and AQP2 and CREB phosphorylation levels (p-AQP2 Ser 256 and p-CREB Ser 133), whereas H89 itself did not exert any significant influences on these variables (Fig. 7, I-L).

Rotatory Stimulus Induces Motion Sickness and Increased Plasma AVP Levels, but Both are Inhibited in Dogs after Vestibular Training. Mozavaptan Reduces, whereas the V2R Agonist Promotes, Motion Sickness in Both Dogs and Rats. We also observed the effects of vestibular training and mozavaptan in dogs to further verify the above experiments in rats. We found an increase in plasma AVP levels after the rotatory test (Fig. 8B); however, vestibular training reduced the rotatory test-induced increase in AVP levels (Fig. 8B), extended the vomiting latency (Fig. 8A), and increased the base plasma AVP levels to some extent (Fig. 8B). Moreover, the V2R antagonist mozavaptan extended the salivation and vomiting latencies in dogs in a dose-dependent manner (Fig. 8, C and D). These results were similar to the anti-motion sickness effects of scopolamine, a positive anti-motion sickness drug, and were consistent with the anti-motion sickness results observed in rats after mozavaptan treatment. In contrast, treatment with the V2R agonist DDAVP before the rotatory test shortened salivation and vomiting latencies in both susceptible and insusceptible dogs in a dose-dependent manner (Fig. 8, E and F). Moreover, identical to the actions of 

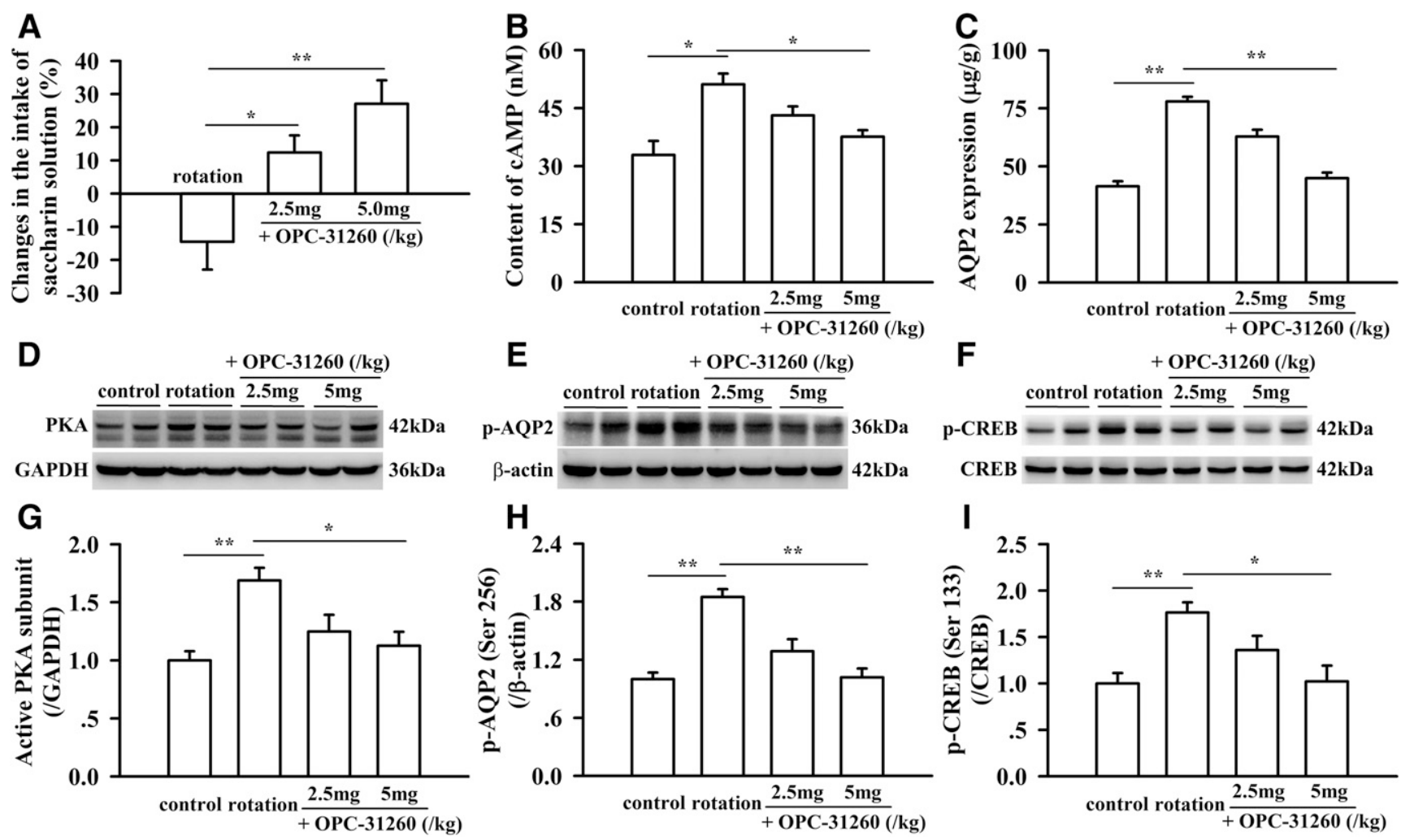

Fig. 6. Changes in V2R-AQP2 pathway signaling in the inner ear and inhibition of rotatory stimulus-induced CTA in rats after systemic treatment with the V2R antagonist. (A) Changes in the intake of $0.15 \%$ saccharin solution by rats after the systemic treatment with mozavaptan (OPC-31260), a V2R antagonist $(n=10)$. (B) Changes in cAMP contents $(n=8)$. (C) Mean values for AQP2 expression measured by ELISA $(n=8)$. (D-F) Western blot analysis for active PKA, p-AQP2, CREB, and p-CREB. (G-I) Mean values for active PKA, p-AQP2, and p-CREB expression, respectively $(n=8)$. $* P<0.05$; $* * P<0.01$.

DDAVP in dogs, treatment of rats with DDAVP induced a conditioned taste aversion to $0.15 \%$ SSS (Fig. $8 \mathrm{G}$ ), which is a confirmed behavioral index for motion sickness (Fig. 8G). However, mozavaptan dose dependently blunted the motion sickness-induced effects of DDAVP in rats after intraperitoneal and intratympanic injections, respectively (Fig. 8H).

\section{Discussion}

The present study first identified that rotatory stimuli, or AVP, activates the inner ear V2R-cAMP-PKA pathway. We also found that AVP treatment of cultured epithelial cells from the endolymphatic sac also activated the V2R-cAMP-PKA pathway and facilitated membrane distribution of AQP2. However, treatment with the V2R antagonist mozavaptan blunted rotatory stimulus- and AVP-induced conditioned taste aversion, a sign of motion sickness in rats. In addition, mozavaptan reduced the changes in the V2R-PKA-AQP2 signaling pathway both in the inner ear of rats after rotatory stimulus and in cultured epithelial cells from rat endolymphatic sacs after AVP perfusion. Similar to the rotatory stimulus and systemic AVP treatment, systemic and intratympanic treatments with the V2R agonist DDAVP also promoted the development of motion sickness in both dogs and rats, suggesting an involvement of inner ear V2R in the development of motion sickness.

The rotatory stimulus-induced increase in cAMP-PKAAQP2 signaling in the inner ear might be related to the increase in plasma AVP concentrations. We found that plasma
AVP concentrations were elevated in dogs and rats after rotatory stimulus and that vestibular training inhibited the increase in plasma AVP concentrations in both dogs and rats and blunted the increase in the V2R-PKA-AQP2 signaling in the rat inner ear. Therefore, the present results suggest that AVP activation of the V2R-PKA-AQP2 pathway in the inner ear is potentially involved in the induction of motion sickness and that V2R may serve as a new target for the development of anti-motion sickness drugs.

Because there is a CREB binding site in the promoter region of the AQP2 gene (Matsumura et al., 1997; Yu et al., 2009), increased CREB phosphorylation in the nucleus after AVP treatment or the increase in plasma AVP levels will induce AQP2 gene transcription and elevate AQP2 expression in kidney collecting duct principal cells, as determined by previous studies (Moeller and Fenton, 2012; Wilson et al., 2013). In the present study, we found that p-CREB Ser 133 levels were elevated in cultured epithelial cells from the endolymphatic sac after AVP perfusion. Therefore, the increased AQP2 expression in the inner ears after rotatory stimulus or AVP injection into the rats could be attributed at least partly to AVP-V2R-cAMP-PKA-CREB pathway activity because inhibiting PKA with H89 reduced the levels of p-AQP2, p-CREB, and AQP2.

Additionally, we noted in our experiments that both V2R mRNA and protein expression levels were temporally reduced after rotatory stimulus and AVP treatment. This is a potential protective responsive expression downregulation that was also observed after AVP treatment in the kidney and in the 
A

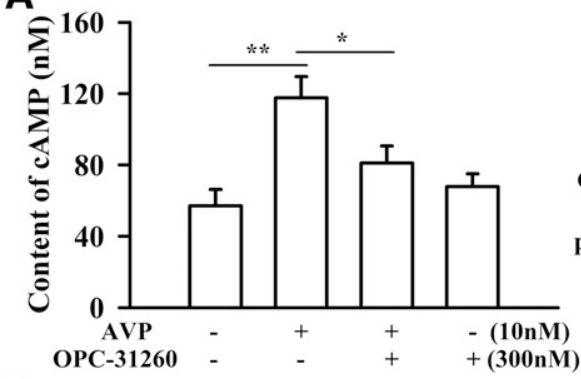

D

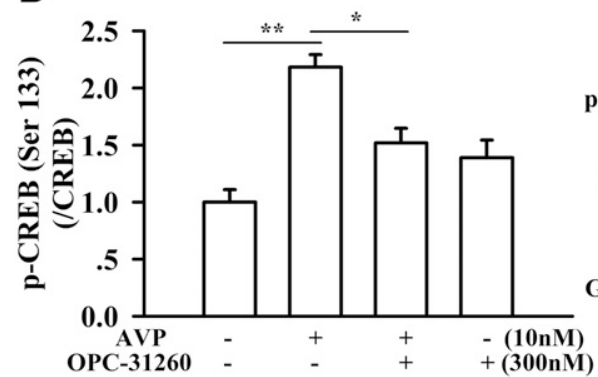

$G$
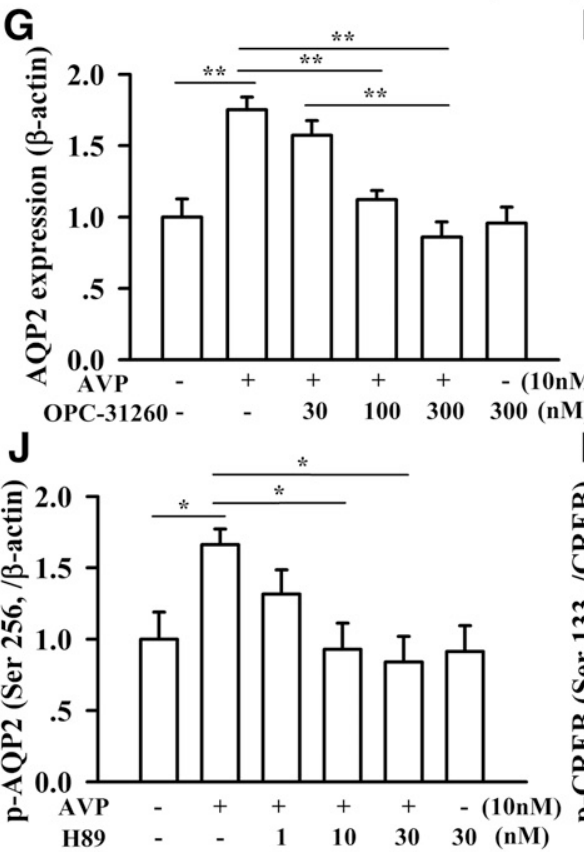

B

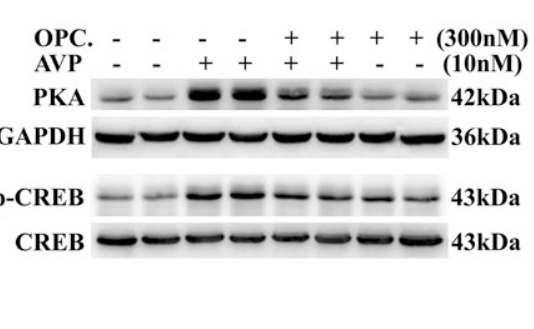

E

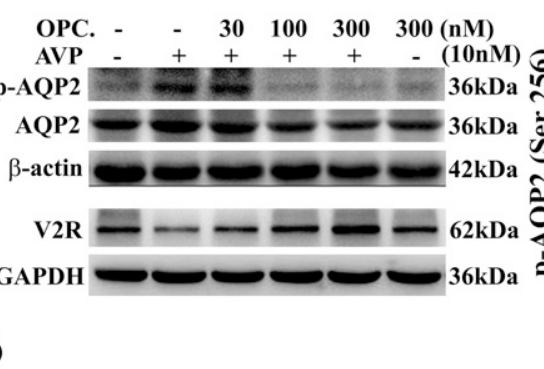

H

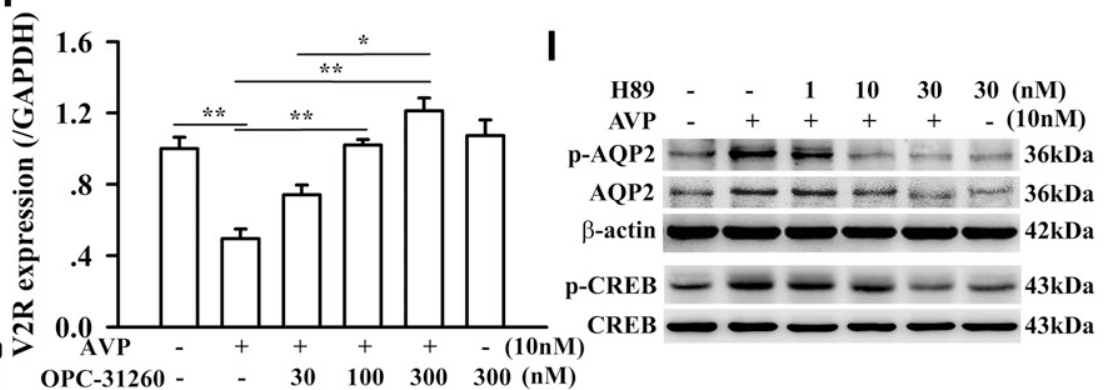

$\mathrm{K}$

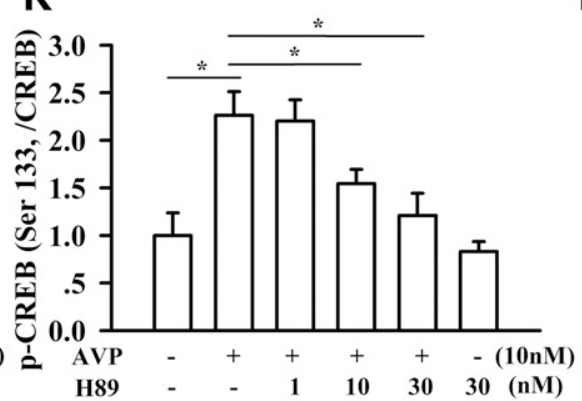

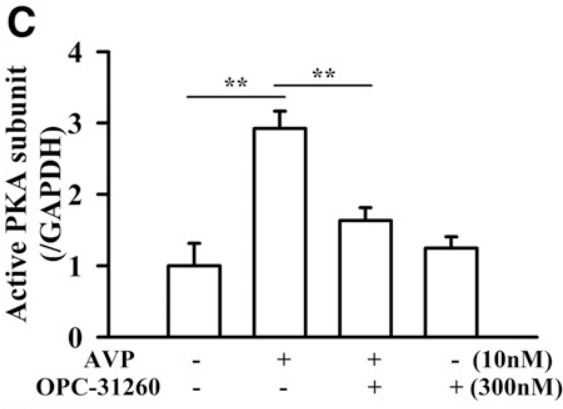

$\mathbf{F}$

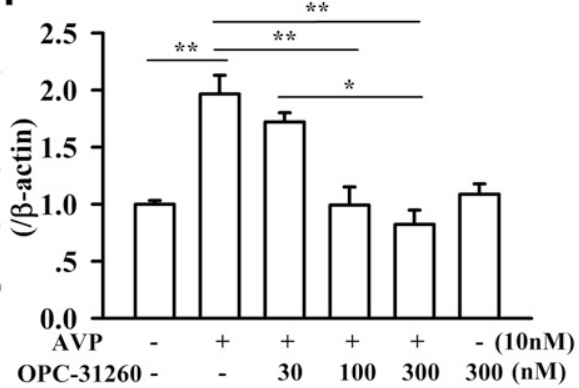

Fig. 7. Inhibition of AVP-induced changes in V2R-AQP2 pathway signaling in cultured epithelial cells from rat endolymphatic sacs after perfusion with the V2R antagonist and PKA inhibitor. (A) Changes in cAMP contents $(n=6)$. (B) Western blot analysis for active PKA, CREB, and p-CREB. (C) Mean values for active PKA expression $(n=6$ ). (D) Mean values for p-CREB expression (/CREB, $n=6$ ). (E) Western blot analysis for AQP2, p-AQP2, and V2R. (F and G) Mean values for p-AQP2 and AQP2 expression, respectively $(n=6)$. (H) Mean values for V2R expression $(n=6)$. (I) Western blot analysis for AQP2, p-AQP2, CREB, and p-CREB expression in the presence of AVP and H89, a PKA inhibitor. (J-L) Mean values for p-AQP2, p-CREB, and AQP2 expression in the presence of AVP and H89 $(n=6)$. *P $<0.05 ; * * P<0.01$.

inner ear by other researchers (Terashima et al., 1998; Kitano et al., 1999; Saito et al., 2001).

The effects of AVP that we observed in the V2R-PKA-AQP2 pathway in the inner ear are similar to those in renal cells (Nielsen et al., 2002; Wilson et al., 2013; Pearce et al., 2015). AVP plays an important role in renal water reabsorption by regulating the membrane insertion and abundance of AQP2, which is primarily mediated by V2R (Moeller and Fenton, 2012). AQP2 has to be phosphorylated for its steady-state localization in the membrane (Kamsteeg et al., 2000; Moeller and Fenton, 2012). In the inner ear, AQP2 is found in membrane structures, including the vascular stria, endolymphatic sac, Reissner's membrane, and Corti's organ (Kumagami et al., 1998; Mhatre et al., 2002; Taguchi et al., 2007; Nishioka et al., 2010; Eckhard et al., 2012; Takumida et al., 2012). The AQP2 protein is expressed on the basal side of the basal cells from the vascular stria, whereas V2Rs are expressed on the apical side of the basal cells (Nishioka et al., 2010; Takumida et al., 2012). AQP2 is also coexpressed with V2R on epithelial cells in the endolymphatic sac (Kumagami et al., 1998; Taguchi et al., 2007; Takumida et al., 2012). We also found the AQP2 distribution in these membrane structures and V2R expression 

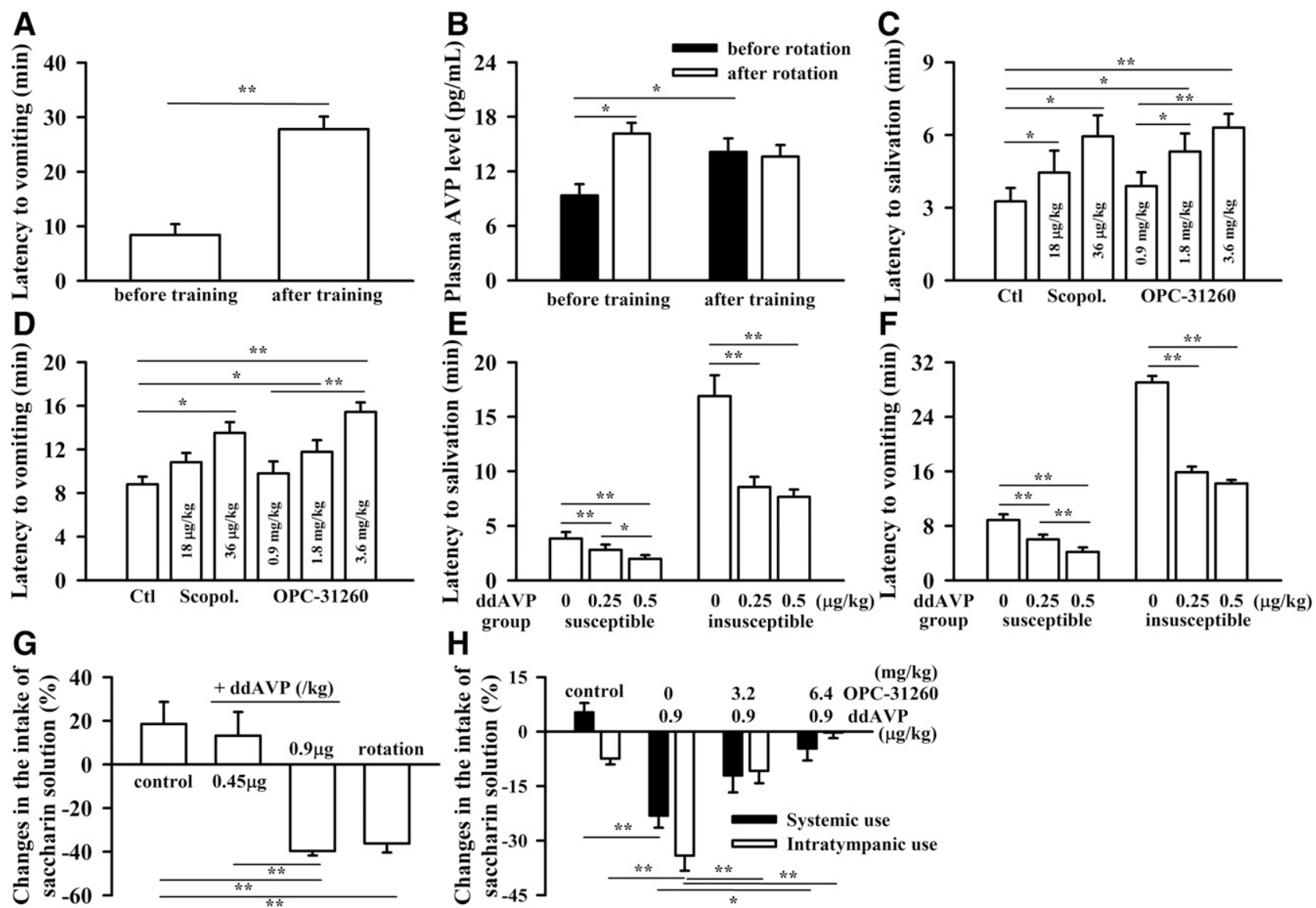

Fig. 8. Reduction in rotatory stimulus-induced motion sickness and plasma AVP elevation after vestibular training and V2R antagonist treatment in dogs and the promotion of motion sickness by the V2R agonist in both dogs and rats. (A) Vomiting latency in dogs during rotatory stimulus $(n=8)$. (B) Changes in AVP plasma levels in dogs $(n=8)$. (C and D) Salivation and vomiting latencies in dogs during rotatory stimulus after mozavaptan (OPC31260 ) and scopolamine treatments $(n=12)$. (E and F) Salivation and vomiting latencies in dogs during rotatory stimulus after intramuscular treatment with DDAVP ( $n=11$ for susceptible group, $n=4$ for insusceptible group). (G) Changes in the intake of $0.15 \%$ saccharin solution by rats after systemic treatment with DDAVP $(n=12)$. (H) Inhibition by mozavaptan (OPC-31260), an AVP V2R antagonist, on CTA induced with DDAVP in rats after systemic and intratympanic uses $(n=10) . * P<0.05$; $* * P<0.01$. Ctl., control; Scopol., scopolamine.

in the inner ear and endolymphatic sac in the present study. Similar to the effects of AQP2 in the kidney, many reports suggest that AQP2 is also involved in the inner ear fluid homeostasis via V2R-mediated regulation of AVP (Kumagami et al., 1998; Mhatre et al., 2002; Sawada et al., 2002; Taguchi et al., 2007; Nishimura et al., 2009a; Nishioka et al., 2010; Eckhard et al., 2012; Takumida et al., 2012). For example, studies on the localization of AQP2 to the basal side of basal cells together with other AQPs and other functional proteins in the vascular stria suggest that AVP-AQP2-mediated water transport might work actively in basal cells from the perilymph toward endolymph, potentially helping form the endolymph (Nishimura et al., 2009a; Nishioka et al., 2010). In contrast, the localization of AQP2 on epithelial cells in the endolymphatic sac also implied that AQP2 may participate in the regulation of endolymph volume (Kumagami et al., 1998; Taguchi et al., 2007; Eckhard et al., 2012; Takumida et al., 2012). Studies by Kakigi et al. (2009) and Nishimura et al. (2009b) indicated that the endolymphatic sac may have both secretary and adsorptive functions in maintaining endolymph homeostasis.

$\mathrm{Gu}$ et al. (2006) found an increase in AQP2 mRNA expression in the rat inner ear after intraperitoneal injection of AVP. Sawada et al. (2002) also found that AQP2 mRNA levels in the cochlea and endolymphatic sac were significantly elevated in rats after intraperitoneal injection of AVP. The results from the present study are consistent with these two reports. Beitz et al. (2003) considered that the physiologic function of the vasopressin effect might be an effective shortterm protection on the endolymph volume during periods of hypovolemia to maintain normal hearing and balance perception. In general, activation of the V2R-PKA-AQP2 pathway in the inner ear and the resulting increase in AQP2 expression and translocation after phosphorylation promotes the production and reduces the resorption of endolymph. However, when AVP levels are pathologically increased over a prolonged period of time, this will overactivate the V2R-PKA-AQP2 pathway in the inner ear, which ultimately leads to enlargement of the intrastrial space (Nishimura et al., 2009a) followed by endolymphatic hydrops (Naftalin, 2001; Beitz et al., 2003; Egami et al., 2013) and abnormal vestibular sensation (Takeda et al., 1995, 2003, 2010; Maekawa et al., 2010).

Rotatory stimulus-induced activation of the V2R-AQP2 system in the inner ear of rats followed by increased plasma AVP levels was identical to that observed in rats after systemic AVP application and in cultured epithelial cells from the endolymphatic sac after in vitro perfusion of AVP in the 
present study. These results were somewhat consistent with studies in animals with experimental endolymphatic hydrops and in patients with Meniere disease, suggesting that motion sickness may have, at least in part, common mechanisms with Meniere disease. Thus, AVP may play a role in the inner ear via $\mathrm{V} 2 \mathrm{R}$ mediation to interfere with the endolymph equilibrium after rotatory stimulation.

Egami et al. (2013) found that administration of DDAVP, a V2R agonist, exacerbated endolymphatic hydrops induced by electrocauterization surgery of the endolymphatic sac in guinea pig and caused temporary vestibular abnormalities that are similar to the vertiginous attacks in patients with Meniere disease. In contrast, Maekawa et al. (2010) found that treatment with mozavaptan, a V2R antagonist, blocked AVPinduced AQP2 translocation in cultured tissues from human endolymphatic sacs. Egami et al. (2016) reported that the systemic application of a low dose of OPC-41061 (tolvaptan), another V2R antagonist, and topical application of this antagonist reduced experimentally induced endolymphatic hydrops. Reports by Takeda et al. revealed that treatment with mozavaptan reduced endolymphatic hydrops induced by surgical obliteration of the endolymphatic duct (Takeda et al., 2006) and by electrocauterization surgery of the endolymphatic sac (Takeda et al., 2003), whereas it decreased AQP2 mRNA levels in both the cochlea and endolymphatic sac (Takeda et al., 2003). In the present study, systemic or intratympanic treatment with the V2R agonist DDAVP promoted the development of motion sickness, whereas the V2R antagonist mozavaptan reduced rotatory stimulus- and AVPinduced motion sickness and inhibited the activation of the V2R-PKA-AQP2 pathway in the inner ear in rats after rotatory stimulus and in cultured epithelial cells from rat endolymphatic sacs after AVP perfusion. Thus, blocking V2R with an antagonist is expected to inhibit the effects of AVP in the inner ear and prevent endolymph equilibrium imbalance, demonstrating that this may become a useful strategy for preventing motion sickness. V2Rs have been found to be distributed mainly in the kidney, inner ear, vascular endothelium, smooth muscle, and some glands (Juul et al., 2014); therefore, targeting this relatively locally distributed receptor with V2R antagonists to prevent motion sickness is advantageous to avoid undesirable CNS side effects of the existing drugs.

In conclusion, the present study further documents the role of AVP in motion sickness. The study suggests that, besides central vasopressin receptor 1 , as reported previously, peripheral, inner ear V2R is also involved. Mozavaptan, a V2R antagonist, improves symptoms in animal models of the disease. V2R antagonism is a potential therapeutic approach in motion sickness.

\section{Authorship Contributions}

Participated in research design: $\mathrm{Xu}$, Zhou, Jiang.

Conducted experiments: Xu, Yang, H.-X. Liu, Xiao, Qiu, J.-X. Wang, Zhao, Gui, G.-Z. Liu, Zhou.

Performed data analysis: Xu, Peng, Li, G.-H. Wang, Zhou, Jiang.

Wrote or contributed to the writing of the manuscript: $\mathrm{Xu}$, Zhou, Jiang.

\section{References}

Abe C, Iwata C, Shiina T, Shimizu Y, and Morita H (2011) Effect of daily linear acceleration training on the hypergravity-induced vomiting response in house musk shrew (Suncus murinus). Neurosci Lett 502:138-142.
Agrup C, Berggren PO, and Bagger-Sjöbäck D (2001) Morphological and functional characteristics of cells cultured from the endolymphatic sac. Hear Res 157:43-51. Azzena GB, Melis F, Caria MA, Teatini GP, and Bozzo G (1993) Vestibular projections to hypothalamic supraoptic and paraventricular nuclei. Arch Ital Biol 131: 127-136.

Beitz E, Zenner HP, and Schultz JE (2003) Aquaporin-mediated fluid regulation in the inner ear. Cell Mol Neurobiol 23:315-329.

Carpenter DO, Briggs DB, and Strominger N (1984) Behavioral and electrophysiological studies of peptide-induced emesis in dogs. Fed Proc 43:2952-2954.

Cheung BS, Kohl RL, Money KE, and Kinter LB (1994) Etiologic significance of arginine vasopressin in motion sickness. J Clin Pharmacol 34:664-670.

Cheung BS, Money KE, Kohl RL, and Kinter LB (1992) Investigation of anti-motion sickness drugs in the squirrel monkey. J Clin Pharmacol 32:163-175.

Crampton GH and Lucot JB (1985) A stimulator for laboratory studies of motion sickness in cats. Aviat Space Environ Med 56:462-465.

Dahlmann A and von Düring M (1995) The endolymphatic duct and sac of the rat: a histological, ultrastructural, and immunocytochemical investigation. Cell Tissue Res 282:277-289.

Eckhard A, Gleiser C, Arnold H, Rask-Andersen H, Kumagami H, Müller M, Hirt B and Löwenheim H (2012) Water channel proteins in the inner ear and their link to hearing impairment and deafness. Mol Aspects Med 33:612-637.

Egami N, Kakigi A, Sakamoto T, Takeda T, Hyodo M, and Yamasoba T (2013) Morphological and functional changes in a new animal model of Ménière's disease. Lab Invest 93:1001-1011.

Egami N, Kakigi A, Takeda T, and Yamasoba T (2016) Dehydration effects of a V2 antagonist on endolymphatic hydrops in Guinea pigs. Hear Res 332:151-159.

Eisenman LM (2009) Motion sickness may be caused by a neurohumoral action of acetylcholine. Med Hypotheses 73:790-793.

Fox RA and McKenna S (1988) Conditioned taste aversion induced by motion is prevented by selective vagotomy in the rat. Behav Neural Biol 50:275-284.

Gallo M, Marquez SL, Ballesteros MA, and Maldonado A (1999) Functional blockade of the parabrachial area by tetrodotoxin disrupts the acquisition of conditioned taste aversion induced by motion-sickness in rats. Neurosci Lett 265:57-60.

Gu FM, Han HL, and Zhang LS (2006) Effects of vasopressin on gene expression in rat inner ear. Hear Res 222:70-78.

Heer M and Paloski WH (2006) Space motion sickness: incidence, etiology, and countermeasures. Auton Neurosci 129:77-79.

Herron DG (2010) The ups and downs of motion sickness. Am J Nurs 110:49-51.

Horii A, Koike K, Uno A, Uno Y, and Kubo T (2001) Vestibular modulation of plasma vasopressin levels in rats. Brain Res 914:179-184.

Hunt MA, Miller SW, Nielson HC, and Horn KM (1987) Intratympanic injection of sodium arsanilate (atoxyl) solution results in postural changes consistent with changes described for labyrinthectomized rats. Behav Neurosci 101:427-428.

Ikegaya Y and Matsuki N (2002) Vasopressin induces emesis in Suncus murinus. Jpn J Pharmacol 89:324-326.

Juul KV, Bichet DG, Nielsen S, and Nørgaard JP (2014) The physiological and pathophysiological functions of renal and extrarenal vasopressin V2 receptors. $A m$ $J$ Physiol Renal Physiol 306:F931-F940.

Kakigi A, Nishimura M, Takeda T, Taguchi D, and Nishioka R (2009) Expression of aquaporin1, 3, and 4, NKCC1, and NKCC2 in the human endolymphatic sac. Auris Nasus Larynx 36:135-139.

Kamsteeg EJ, Heijnen I, van Os CH, and Deen PM (2000) The subcellular localization of an aquaporin-2 tetramer depends on the stoichiometry of phosphorylated and nonphosphorylated monomers. J Cell Biol 151:919-930.

Kim MS, Chey WD, Owyang C, and Hasler WL (1997) Role of plasma vasopressin as a mediator of nausea and gastric slow wave dysrhythmias in motion sickness. Am J Physiol 272:G853-G862.

Kitano H, Suzuki M, Kitanishi T, Yazawa Y, Kitajima K, Isono T, Takeda T, Kimura $\mathrm{H}$, and Tooyama I (1999) Regulation of inner ear fluid in the rat by vasopressin. Neuroreport 10:1205-1207.

Kozarsky PE (1998) Prevention of common travel ailments. Infect Dis Clin North Am 12:305-324.

Kumagami H, Loewenheim H, Beitz E, Wild K, Schwartz H, Yamashita K, Schultz J, Paysan J, Zenner HP, and Ruppersberg JP (1998) The effect of anti-diuretic hormone on the endolymphatic sac of the inner ear. Pflugers Arch 436:970-975.

Kumagami H, Terakado M, Sainoo Y, Baba A, Fujiyama D, Fukuda T, Takasaki K, and Takahashi $\mathrm{H}$ (2009) Expression of the osmotically responsive cationic channel TRPV4 in the endolymphatic sac. Audiol Neurotol 14:190-197.

Li X, Jiang ZL, Wang GH, and Fan JW (2005) Plasma vasopressin, an etiologic factor of motion sickness in rat and human? Neuroendocrinology 81:351-359.

Lien HC, Sun WM, Chen YH, Kim H, Hasler W, and Owyang C (2003) Effects of ginger on motion sickness and gastric slow-wave dysrhythmias induced by circular vection. Am J Physiol Gastrointest Liver Physiol 284:G481-G489.

Liu B, Leng Y, Zhou R, Liu J, Liu D, Zhang SL, and Kong WJ (2016) Intratympanic steroids injection is effective for the treatment of drop attacks with Ménière's disease and delayed endolymphatic hydrops: a retrospective study. Medicine Baltimore) 95:e5767.

Liu F, Inokuchi A, and Komiyama S (1997) Neuronal responses to vestibular stimulation in the Guinea pig hypothalamic paraventricular nucleus. Eur Arch Otorhinolaryngol 254:95-100.

Liu J, Wang L, and Chen JD (2004) Effects of intestinal electrical stimulation on intestinal dysrhythmia and symptoms in dogs. Dig Dis Sci 49:720-728.

Maekawa C, Kitahara T, Kizawa K, Okazaki S, Kamakura T, Horii A, Imai T, Doi K Inohara H, and Kiyama H (2010) Expression and translocation of aquaporin-2 in the endolymphatic sac in patients with Meniere's disease. J Neuroendocrinol 22:1157-1164.

Markia B, Kovács ZI, and Palkovits M (2008) Projections from the vestibular nuclei to the hypothalamic paraventricular nucleus: morphological evidence for the existence of a vestibular stress pathway in the rat brain. Brain Struct Funct 213:239-245.

Matsumura Y, Uchida S, Rai T, Sasaki S, and Marumo F (1997) Transcriptional regulation of aquaporin-2 water channel gene by cAMP. J Am Soc Nephrol 8: 861-867. 
Mhatre AN, Jero J, Chiappini I, Bolasco G, Barbara M, and Lalwani AK (2002) Aquaporin-2 expression in the mammalian cochlea and investigation of its role in Meniere's disease. Hear Res 170:59-69.

Moeller HB and Fenton RA (2012) Cell biology of vasopressin-regulated aquaporin-2 trafficking. Pflugers Arch 464:133-144.

Naftalin L (2001) Endolymphatic hydrops induced by chronic administration of vasopressin. Hear Res 155:181-182.

Nielsen S, Frøkiaer J, Marples D, Kwon TH, Agre P, and Knepper MA (2002) Aquaporins in the kidney: from molecules to medicine. Physiol Rev 82:205-244.

Nishimura M, Kakigi A, Takeda T, Okada T, and Doi K (2009a) Time course changes of vasopressin-induced enlargement of the rat intrastrial space and the effects of a vasopressin type 2 antagonist. Acta Otolaryngol 129:709-715.

Nishimura M, Kakigi A, Takeda T, Takeda S, and Doi K (2009b) Expression of aquaporins, vasopressin type 2 receptor, and $\mathrm{Na}+{ }_{-} \mathrm{K}_{+}-\mathrm{Cl}^{-}$cotransporters in the rat endolymphatic sac. Acta Otolaryngol 129:812-818.

Nishioka R, Takeda T, Kakigi A, Okada T, Takebayashi S, Taguchi D, Nishimura M, and Hyodo M (2010) Expression of aquaporins and vasopressin type 2 receptor in the stria vascularis of the cochlea. Hear Res 260:11-19.

Ossenkopp KP (1983) Area postrema lesions in rats enhance the magnitude of body rotation-induced conditioned taste aversions. Behav Neural Biol 38:82-96.

Pearce D, Soundararajan R, Trimpert C, Kashlan OB, Deen PM, and Kohan DE (2015) Collecting duct principal cell transport processes and their regulation. Clin J Am Soc Nephrol 10:135-146.

Saito T, Higashiyama M, Nagasaka S, Sasaki S, Saito T, and Ishikawa SE (2001) Role of aquaporin-2 gene expression in hyponatremic rats with chronic vasopressin-induced antidiuresis. Kidney Int 60:1266-1276.

Sawada S, Takeda T, Kitano H, Takeuchi S, Kakigi A, and Azuma H (2002) Aquaporin-2 regulation by vasopressin in the rat inner ear. Neuroreport 13 $1127-1129$.

Sutton RL, Fox RA, and Daunton NG (1988) Role of the area postrema in three putative measures of motion sickness in the rat. Behav Neural Biol 50:133-152.

Taguchi D, Takeda T, Kakigi A, Takumida M, Nishioka R, and Kitano H (2007) Expressions of aquaporin-2, vasopressin type 2 receptor, transient receptor potential channel vanilloid (TRPV)1, and TRPV4 in the human endolymphatic sac. Laryngoscope 117:695-698.

Taillemite JP, Devaulx P, and Bousquet F (1997) Motion sickness. Med Trop (Mars) 57:483-487.

Takeda T, Kakigi A, and Saito H (1995) Antidiuretic hormone (ADH) and endolymphatic hydrops. Acta Otolaryngol Suppl 519:219-222.

Takeda T, Sawada S, Takeda S, Kitano H, Suzuki M, Kakigi A, and Takeuchi S (2003) The effects of V2 antagonist (OPC-31260) on endolymphatic hydrops. Hear Res 182:9-18.

Takeda T, Takeda S, Kakigi A, Okada T, Nishioka R, and Taguchi D (2006) A comparison of dehydration effects of V2-antagonist (OPC-31260) on the inner ear between systemic and round window applications. Hear Res 218:89-97.
Takeda T, Takeda S, Kakigi A, Okada T, Nishioka R, Taguchi D, Nishimura M, and Nakatani H (2010) Hormonal aspects of Ménière's disease on the basis of clinical and experimental studies. ORL J Otorhinolaryngol Relat Spec 71 (Suppl 1): $1-9$

Takumida M and Anniko M (2006) Protective effect of edaravone against the ototoxicity of Pseudomonas aeruginosa exotoxin A. Acta Otolaryngol 126:15-19.

Takumida M, Kakigi A, Egami N, Nishioka R, and Anniko M (2012) Localization of aquaporins 1, 2, and 3 and vasopressin type 2 receptor in the mouse inner ear. Acta Otolaryngol 132:807-813.

Tatewaki M, Strickland C, Fukuda H, Tsuchida D, Hoshino E, Pappas TN, and Takahashi T (2005) Effects of acupuncture on vasopressin-induced emesis in conscious dogs. Am J Physiol Regul Integr Comp Physiol 288:R401-R408.

Terashima Y, Kondo K, Mizuno Y, Iwasaki Y, and Oiso Y (1998) Influence of acute elevation of plasma AVP level on rat vasopressin V2 receptor and aquaporin-2 mRNA expression. J Mol Endocrinol 20:281-285.

Tighilet B, Manrique C, and Lacour M (2009) Stress axis plasticity during vestibular compensation in the adult cat. Neuroscience 160:716-730.

Warwick-Evans LA, Symons N, Fitch T, and Burrows L (1998) Evaluating sensory conflict and postural instability. Theories of motion sickness. Brain Res Bull $\mathbf{4 7}$ 465-469.

Wilson JL, Miranda CA, and Knepper MA (2013) Vasopressin and the regulation of aquaporin-2. Clin Exp Nephrol 17:751-764.

Xu LH, Tang GR, Yang JJ, Liu HX, Li JC, and Jiang ZL (2015) AVP modulation of the vestibular nucleus via V1b receptors potentially contributes to the development of motion sickness in rat. Mol Brain 8:86.

Yu MJ, Miller RL, Uawithya P, Rinschen MM, Khositseth S, Braucht DW, Chou CL Pisitkun T, Nelson RD, and Knepper MA (2009) Systems-level analysis of cellspecific AQP2 gene expression in renal collecting duct. Proc Natl Acad Sci USA 106:2441-2446.

Zou J and Pyykkö I (2016) Calcium metabolism profile in rat inner ear indicated by MRI after tympanic medial wall administration of manganese chloride. Ann Otol Rhinol Laryngol 125:53-62.

Address correspondence to: Dr. Xin Zhou, Department of Neurophysiology and Neuropharmacology, Institute of Special Environmental Medicine, Institute of Nautical Medicine and Co-innovation Center of Neuroregeneration, Nantong University, 9 Seyuan Rd., Chongchuan District, Nantong, Jiangsu, 226019, China. E-mail: zhouxin_2046@126.com; or Dr. Zheng-Lin Jiang, Department of Neurophysiology and Neuropharmacology, Institute of Special Environmental Medicine, Institute of Nautical Medicine and Co-innovation Center of Neuroregeneration, Nantong University, 9 Seyuan Rd., Chongchuan District, Nantong, Jiangsu, 226019, China. E-mail: jiangzl@ntu.edu.cn 